\title{
Pectin Methylesterases: Cell Wall Remodeling Proteins Are Required for Plant Response to Heat Stress
}

\author{
Hui-Chen $W^{1}$, Victor P. Bulgakov ${ }^{2}$ and Tsung-Luo Jinn ${ }^{3 *}$ \\ 1 Department of Biological Sciences and Technology, National University of Tainan, Tainan, Taiwan, ${ }^{2}$ Institute of Biology \\ and Soil Science, Far Eastern Branch of the Russian Academy of Sciences, Vladivostok, Russia, ${ }^{3}$ Department of Life \\ Science, Institute of Plant Biology, National Taiwan University, Taipei, Taiwan
}

\section{OPEN ACCESS}

Edited by: Motoaki Seki, RIKEN, Japan

Reviewed by:

Niranjan Chakraborty, National Institute of Plant Genome Research (NIPGR), India

Jenny C. Mortimer,

Lawrence Berkeley National Laboratory (LBNL), United States

*Correspondence:

Tsung-Luo Jinn jinnt@ntu.edu.tw

Specialty section:

This article was submitted to Plant Abiotic Stress,

a section of the journal

Frontiers in Plant Science

Received: 03 July 2018

Accepted: 17 October 2018

Published: 06 November 2018

Citation:

Wu H-C, Bulgakov VP and

Jinn T-L (2018) Pectin

Methylesterases: Cell Wall Remodeling Proteins Are Required for Plant Response to Heat Stress.

Front. Plant Sci. 9:1612.

doi: 10.3389/fp/s.2018.01612
Heat stress (HS) is expected to be of increasing worldwide concern in the near future, especially with regard to crop yield and quality as a consequence of rising or varying temperatures as a result of global climate change. HS response (HSR) is a highly conserved mechanism among different organisms but shows remarkable complexity and unique features in plants. The transcriptional regulation of HSR is controlled by HS transcription factors (HSFs) which allow the activation of HS-responsive genes, among which HS proteins (HSPs) are best characterized. Cell wall remodeling constitutes an important component of plant responses to HS to maintain overall function and growth; however, little is known about the connection between cell wall remodeling and HSR. Pectin controls cell wall porosity and has been shown to exhibit structural variation during plant growth and in response to HS. Pectin methylesterases (PMEs) are present in multigene families and encode isoforms with different action patterns by removal of methyl esters to influencing the properties of cell wall. We aimed to elucidate how plant cell walls respond to certain environmental cues through cell wall-modifying proteins in connection with modifications in cell wall machinery. An overview of recent findings shed light on PMEs contribute to a change in cell-wall composition/structure. The finescale modulation of apoplastic calcium ions $\left(\mathrm{Ca}^{2+}\right)$ content could be mediated by PMEs in response to abiotic stress for both the assembly and disassembly of the pectic network. In particular, this modulation is prevalent in guard cell walls for regulating cell wall plasticity as well as stromal aperture size, which comprise critical determinants of plant adaptation to HS. These insights provide a foundation for further research to reveal details of the cell wall machinery and stress-responsive factors to provide targets and strategies to facilitate plant adaptation.

Keywords: cell wall remodeling, heat stress response, guard cell wall, pectin, pectin methylesterase

Abbreviations: ABA, abscisic acid; AGA, apiogalacturonan; $\mathrm{Ca}^{2+}$, calcium ion; CaM, calmodulin; CBK3, CaM-binding protein kinase 3; CesA, cellulose synthase; CSLD5, cellulose synthase-like protein; CTL1, chitinase-like protein; DM, degree of methylesterification; EXP, expansin; GalA, galacturonic acid; HGA, homogalacturonan; HIT4, heat-intolerant 4; HS, heat stress; HSBP, HSF-binding protein; HSE, heat shock element; HSF, heat shock transcription factor; HSP, heat stress protein; HSR, heat stress response; MeOH, methanol; miRNA, microRNA; MP, movement protein; NF-YC10, nuclear factor Y, subunit C10; NPG1, no pollen germination 1; OG, oligogalacturonide; ORF, open reading frame; PAE, pectin acetylesterase; PG, polygalacturonase; PL, pectin lyase; PLL, pectate lyase-like protein; PME, pectin methylesterase; PME34, pectin methylesterase 34; PMEI, PME inhibitor; QRT1, QUARTET 1; RG-I, rhamnogalacturonan-I; RG-II, rhamnogalacturonan-II; ROS, reactive oxygen species; sHSP, small heat shock protein; siRNA, small interfering RNA; VGD1, VANGUARD 1; WAK, wall-associated kinase; XET/XTH, xyloglucan endotransglycosylase/hydrolase; XGA, xylogalacturonan. 


\section{INTRODUCTION}

Plants face challenges of extreme environmental conditions, which include various abiotic and biotic stresses, all of which exert adverse effects on plant growth and development. Being sessile organisms, plants cannot move to favorable environments; accordingly, they have developed a remarkable number of strategies to mitigate environmental impacts. Global climate change constitutes one of the most detrimental stresses to plants because it is driving an increase in ambient temperatures, which, according to the Intergovernmental Panel on Climate Change prediction (IPCC, 2012), are expected to be $2-5^{\circ} \mathrm{C}$ higher than the current temperatures by the late twenty-first century. Extremely high temperatures can cause devastating damage to crops and reduce crop production; however, plant cells have been shown to have elaborate systems to respond to a variety of challenges, including HSR, which can improve crop yield under climate change conditions.

Acquired thermotolerance in plants consists of translating an initial moderate temperature increment into molecular defenses against subsequent extreme temperatures, such as preventing and repairing damage to heat-labile proteins and membranes (Larkindale and Vierling, 2008). HSR is characterized by the induction of a large set of HSPs, many of which comprise chaperone proteins that assist in protein folding and protect cellular homeostasis against heat and other stress stimuli (Morimoto, 2008). In addition to the induction of HS-responsive genes, the modification of biophysical properties of the cell wall may represent a key component in responding to environmental injuries. For example, $\mathrm{HS}$ at $37^{\circ} \mathrm{C}$ can generate changes in cell wall polymers in coffee (Coffea arabica) leaves, resulting in $\sim 50 \%$ decrease in pectin and $40 \%$ increase in hemicellulose (Lima et al., 2013). Thus, the modulation of plant cell walls, which comprise a dynamic and interconnected network consisting of a heterogeneous matrix with diverse biochemical and mechanical properties, has emerged as an important strategy in plant stress responses.

Pectic polysaccharides are highly heterogeneous polymers involved in the control of cell wall porosity and constitute the major adhesive material between cells (Willats et al., 2001). When the cell is challenged with stress conditions, specific transcriptional responses affect the production of certain cell wall proteins, leading to crucial changes in cell wall architecture (Klis et al., 2006). Pectin modification is catalyzed by a large enzyme family of PMEs that reside in the cell wall and which modulate apoplastic $\mathrm{Ca}^{2+}$ content in response to stresses for both the assembly and disassembly of the pectic network (Micheli, 2001; Wu and Jinn, 2010; Wu et al., 2010). Thus, the maintenance of cell wall integrity is tightly controlled and strictly coordinated with the stress response in plant cells. Pectins have been identified as key elements in plant responses to either heat or cold temperature stress in various species such as winter oilseed rape (Brassica napus var. oleifera), bromeliad (Nidularium minutum), Arabidopsis (Arabidopsis thaliana), rice (Oryza sativa), soybean (Glycine max), and coffee (Wu and Jinn, 2010; Carvalho et al., 2013;
Huang et al., 2017). However, the cell wall factors that contribute to the development of plant thermotolerance remain largely unknown.

A previous review revealed that PME-mediated changes in the cell wall have played a role in various vegetative and reproductive developmental processes in Arabidopsis and other dicotyledons (Wolf et al., 2009). The DM of HGAs can be controlled by PMEs that have the capacity to remove methyl ester groups to contribute to the intercellular adhesion during plant development and stress responses (Wu et al., 2010; Le Gall et al., 2015). Thus, the DM constitutes a key element in the control of the wall stiffness and hydration status of the pectic matrix during abiotic stresses. PMEs exhibit a potential for the development of thermotolerance by maintaining apoplastic $\mathrm{Ca}^{2+}$ homeostasis (Wu et al., 2010). Heat-activated PME activity is involved in the cell-wall localization of $\mathrm{Ca}^{2+}$, i.e., with the removal of apoplastic $\mathrm{Ca}^{2+}$ that participates in $\mathrm{HS}$ signaling to induce HSP expression and cell-wall remodeling to retain plasma membrane integrity, thus preventing cellular content leakage and conferring thermoprotection (Wu and Jinn, 2010). Furthermore, through the identification of Arabidopsis PME34 mutant plants, it was verified that the thermotolerance impairment of pme34 was independent from the expression of HS-responsive genes; whereas PME34 functions in controlling stomatal movements and in regulating the flexibility of the guard cell wall required for heat response (Huang et al., 2017).

Little is known about the dynamics of the pectin matrix in the regulation of the impact of stress on plants. In previous research, we focused on the role of the PME, which is intrinsically involved in the modification of cell wall components in response to HS; and most recently demonstrated that the dynamic network of cell wall remodeling proteins with enzymatic activity is crucially important for cell wall tolerance to HS (Wu and Jinn, 2010; Wu et al., 2010, 2017; Huang et al., 2017). The present review, therefore, describes the most recent findings regarding cell wall remodeling and HSR as well as specific issues with the characterization of PME. In addition, this review also highlights the diversity of their roles during plant development and in response to diverse abiotic stresses, particularly to HS.

\section{REGULATION OF THE HEAT STRESS RESPONSE IN PLANTS}

Heat stress causes a broad spectrum of cellular damage through the extensive denaturation and aggregation of proteins, and by modifying membrane permeability and fluidity, which subsequently disrupts the balance of metabolic processes. In nature, such HS conditions may be chronic or recurring, or both (Bäurle, 2016); therefore, plants have developed diverse systems to cope with recurring stress. HSR is a highly conserved stress response mechanism that reflects how plants respond and adapt to HS through improved thermotolerance. It defines all high temperature-related defense activities used in the cell to prevent damage and aggregation at the proteome level (Lindquist and Craig, 1988; Vierling, 1991). 
The induction of HSPs constitutes one of the bestcharacterized responses in the adaptation to elevated temperature and plays an important role in the acquisition of thermotolerance. Recently, epigenetic mechanisms have been found to play important roles in the regulation of HSR, including DNA methylation (Boyko et al., 2010; Folsom et al., 2014; Lämke and Bäurle, 2017), histone modification (Min et al., 2014), histone variants (Kumar and Wigge, 2010), ATP-dependent chromatin remodeling (Mlynárová et al., 2007), and siRNAs and miRNAs (Ito et al., 2011; Ballén-Taborda et al., 2013). For example, miRNA 156,160 , and 172 modulation of HSP gene induction is required for Arabidopsis thermotolerance (Khraiwesh et al., 2012; Lin et al., 2018). Accumulation of the heat-induced retrotransposon ONSEN, which is recognized by HS transcription factors HsfA1 and HsfA2 through its HSE, is required for the regulation of HS memory (Ito et al., 2011; Cavrak et al., 2014; Ohama et al., 2017). Arabidopsis HIT4 is a chromocenter-localized protein that functions as a regulator of stress-triggered chromatin reorganization that is essential for plant heat tolerance (Wang et al., 2013). Therefore, it appears as if the epigenetic control of heat-responsive gene expression is frequently utilized to prevent heat-related damages (Liu et al., 2015; Lämke and Bäurle, 2017; Ohama et al., 2017). Furthermore, the emerging evidence indicates that cell wall remodeling plays a crucial role in the response to HS through the activation of cell wall-related genes and alteration of cell wall compositions ( $\mathrm{Wu}$ and Jinn, 2010; Wu et al., 2010, 2017; Huang et al., 2017). Thus, the modification of cell wall structures to enhance their functions to perceive and respond to multiple environmental stresses is crucial for plants by imparting stress endurance. We summarize the current knowledge regarding plant HSR with different aspects to integrate cellular compartments and signaling networks as addressed in Figure 1.

\section{Plant Heat Stress Transcription Factor-Mediated Heat Stress Transcriptional Network}

The inherent ability of plants to tolerate temperatures above those that are optimal for growth is termed basal (or intrinsic) thermotolerance (Larkindale et al., 2005). Plants also have the ability to acquire tolerance to otherwise lethal HS, referred to as acquired thermotolerance (or HS priming). Specifically, mild HS primes a plant to subsequently withstand or to acclimate to high temperatures that would otherwise be lethal to an unadapted plant (Mittler et al., 2012). This priming response of plants can be maintained over several days after mild HS and a return to normal growth conditions; which is referred to as the maintenance of acquired thermotolerance or HS memory (Charng et al., 2006, 2007; Stief et al., 2014). However, the molecular mechanisms involved in plant HS-priming and HSmemory remain largely unknown, especially for HS memory (Bäurle, 2016). In brief, heat stress transcription factors (HSFs) act as central regulators of HS priming by recognizing the conserved HSE in the promoter of the genes encoding HSP (Scharf et al., 1990), which in turn guard the proteome from misfolding and aggregation under heat conditions. The HSBP is a negative regulator of HSR through the interaction with HSF and thus dissociates trimeric HSFs for the attenuation of HSR (Satyal et al., 1998; Fu et al., 2002; Hsu et al., 2010; Rana et al., 2012). The regulation of HSFs in response to HS is illustrated in Figure 2A.

Four homologs of HsfA1 (HsfAla, b, d, e) play roles of master regulators for acquired thermotolerance in Arabidopsis (Liu et al., 2011). HsfA2 has been shown to act as a secondary regulator under the control of HsfA1s to trigger a transcriptional cascade for the induction of early and late HS-responsive genes (Busch et al., 2005; Charng et al., 2007). Arabidopsis HsfB1 can act as a transcriptional repressor during the attenuation of HSR, whereas tomato (Solanum lycopersicum) HsfB1 possesses both coactivator and repressor functions (Bharti et al., 2004; Ikeda et al., 2011). Two major regulators of HSR, HsfA1s and dehydration-responsive element-binding protein $2 \mathrm{~A}$, are controlled by other regulatory factors such as NF-YC10, Hsp90, Hsp70, and small HSP (sHSP) (Hahn et al., 2011; Sato et al., 2014), with regard to their activation or inactivation in the early HSR or an unstressed condition. In addition, phytohormone ABA is also involved in HS signaling through the regulation of HsfA6b for plant thermotolerance (Huang et al., 2016). In yeast (Saccharomyces cerevisiae), Hsfl in collaboration with protein kinase PKC1 regulates heat-induced cell-wall genes, including CWP1, SPI1, HOR7, YGP1, and ZEO1, to mediate maintenance of cell-wall integrity under HS (Imazu and Sakurai, 2005). Thus, yeast Hsf1 plays a role not only in the induction of HSPs expression but also in the induction of a set of cell-wall genes involved in cell-wall formation and remodeling to prevent cell lysis at high temperature. These data raise the question whether plant HSFs function as yeast Hsf1 involved in cell wall remodeling. Further work is required to determine the role of HSFs encoding a variety of other proteins that specifically function in plant cell-wall organization under HS.

\section{$\mathrm{Ca}^{2+} /$ Calmodulin-Mediated Heat Stress Signaling}

Despite the ubiquitous nature of the HSR, little is known about how plants sense an elevating temperature to transmit a signal that results in HSP induction and acquired thermotolerance. One candidate molecule that serves as a second messenger during HS signaling is calcium $\left(\mathrm{Ca}^{2+}\right)$, a ubiquitous signal in eukaryotic cells. $\mathrm{Ca}^{2+}$ signals were shown to manifest through transient changes of spatio-temporal patterns of free cytosolic $\mathrm{Ca}^{2+}$ content $\left(\left[\mathrm{Ca}^{2+}\right]_{\text {cyt }}\right)$ arising from the flux of $\mathrm{Ca}^{2+}$ into the cytosol, defining the so-called $\mathrm{Ca}^{2+}$ signature (Dodd et al., 2010). A stress-induced change in $\left[\mathrm{Ca}^{2+}\right]_{\text {cyt }}$ might constitute one of the primary transduction mechanisms whereby gene expression and biochemical events are altered to adapt to environmental stresses (Monroy and Dhindsa, 1995). The rise time, peak value, and duration of the decay back to resting levels of $\mathrm{Ca}^{2+}$ transients generated by early events have been implicated in controlling different transduction processes, including changes in gene expression (Dolmetsch et al., 1997; Kim et al., 2009). Depending on the specific activation properties, $\mathrm{Ca}^{2+}$ channels, $\mathrm{Ca}^{2+}$-ATPases, and $\mathrm{Ca}^{2+} / \mathrm{H}^{+}$antiporters as modulators of $\mathrm{Ca}^{2+}$ shape the parameters and spatial characteristics of the $\mathrm{Ca}^{2+}$ flux, 


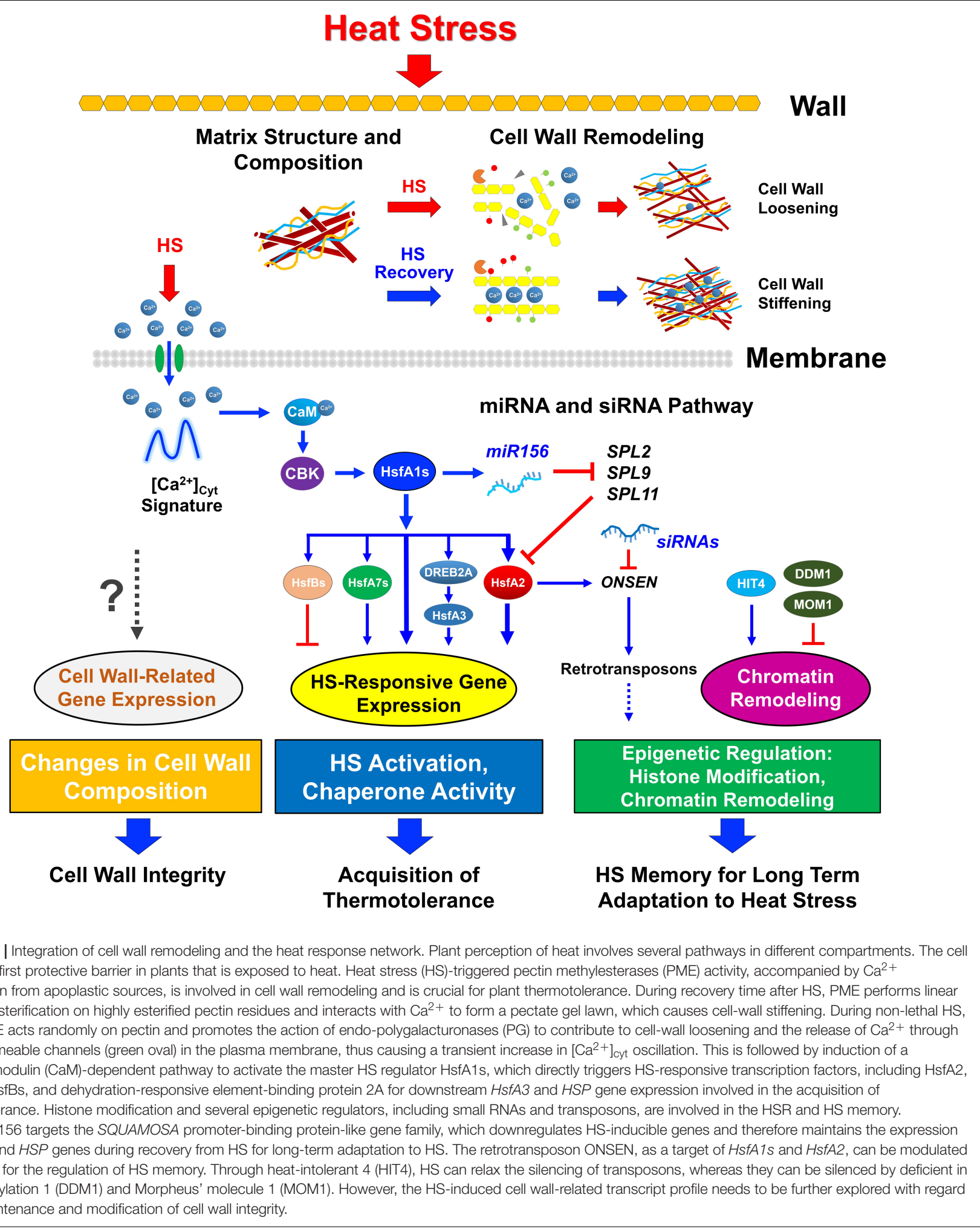

resulting in distinct a $\mathrm{Ca}^{2+}$ signature in response to different stress stimuli (Demidchik and Maathuis, 2007) (Figure 2B).

The stress-induced intracellular $\mathrm{Ca}^{2+}$ levels can be transmitted and sensed by a toolkit of $\mathrm{Ca}^{2+}$-binding proteins such as CaMs and their related-proteins, such as CaM-like proteins, calcineurin $\mathrm{B}$-like proteins, and $\mathrm{Ca}^{2+}$-dependent protein kinases, for downstream responses. CaMs are highly conserved, consisting of two globular domains, each with 
A
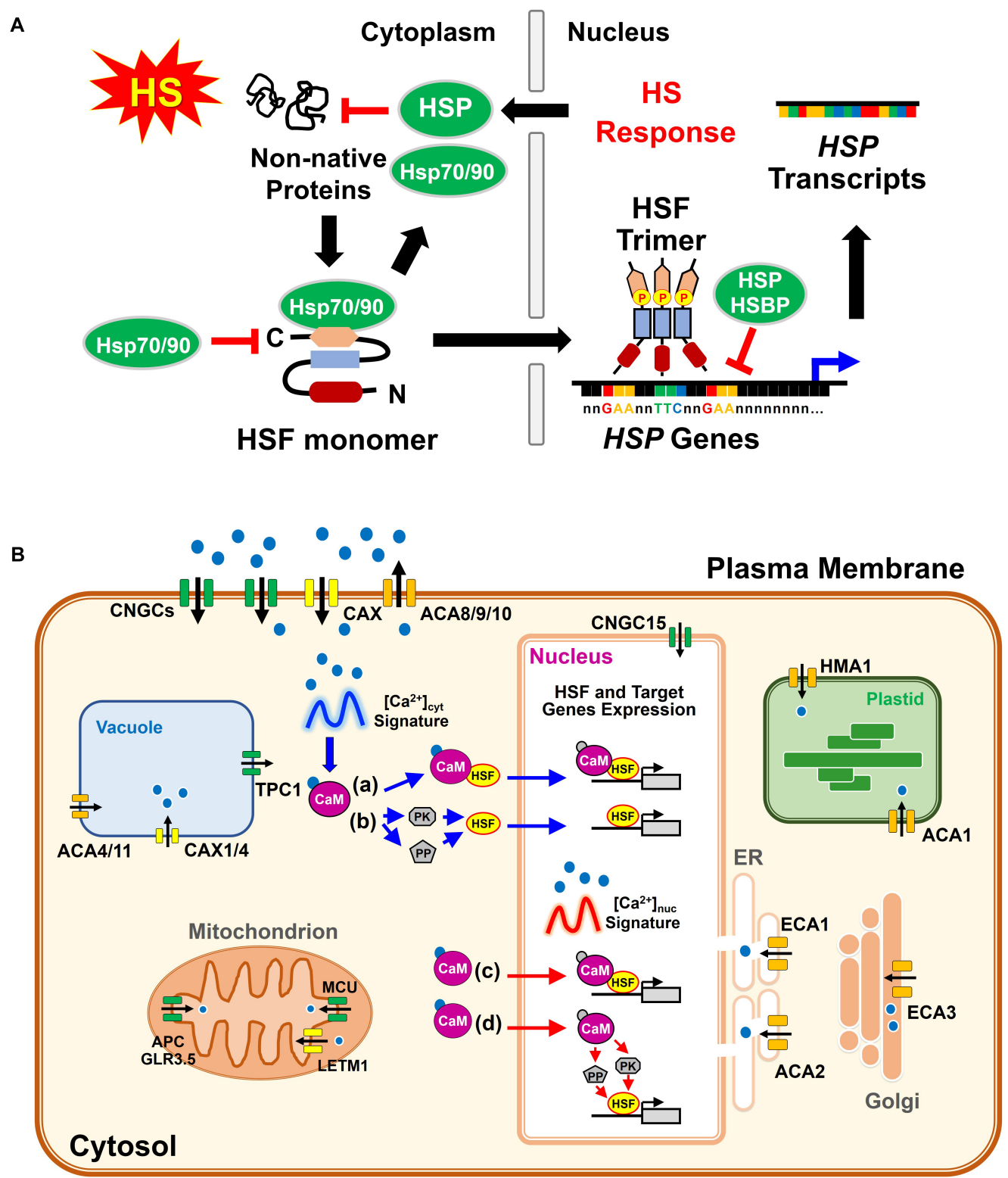

$\mathrm{Ca}^{2+}$ Flux $\mathrm{Ca}^{2+} \square \mid \square \mathrm{Ca}^{2+}$-permeable Channel $\square \mid \square \mathrm{Ca}^{2+} / \mathrm{H}^{+}$Antiporter $\square \mid \square$ P-ATPase

FIGURE 2 | Basic function of plant HSF and HS-induced $\left[\mathrm{Ca}^{2+}\right]_{\text {cyt } / \text { nuc }}$ Oscillation interpretation by CaM in response to heat. (A) Under unstressed conditions, $\mathrm{Hsp70/HspP90} \mathrm{can} \mathrm{directly} \mathrm{regulate} \mathrm{the} \mathrm{function} \mathrm{of} \mathrm{HSF} \mathrm{by} \mathrm{blocking} \mathrm{its} \mathrm{transcriptional} \mathrm{activity.} \mathrm{Upon} \mathrm{HS,} \mathrm{non-native} \mathrm{proteins} \mathrm{induce} \mathrm{the} \mathrm{conversion} \mathrm{of} \mathrm{monomeric}$ HSF into an active trimeric form, which is phosphorylated and translocated into the nucleus. HSF trimer, with high-affinity DNA binding capacity to the HSE ( $5^{\prime}$-nGAAnnTTCnnGAAn-3') of the HSP gene promoter region, activates HSP gene expression, whereas it is downregulated by the interaction of HSP and HSBP with the HSF trimer to attenuate HSR in plants. HSP production and relocation to the cytoplasm inhibits non-native protein misfolding and aggregation. (B) Cellular $\mathrm{Ca}^{2+}$ transport is tightly controlled within all membrane-bound organisms during heat stress. An increase in $\left[\mathrm{Ca}^{2+}\right]_{\mathrm{cyt}}$ is manifested by $\mathrm{Ca}^{2+}$ influx to the cytosol, mediated by $\mathrm{Ca}^{2+}$-permeable ion channels, either from the apoplast across the plasma membrane, or from intracellular stores such as the endoplasmic reticulum or vacuole. In contrast, $\mathrm{Ca}^{2+}$-ATPases and the $\mathrm{Ca}^{2+} / \mathrm{H}^{+}$antiporter systems are responsible for $\mathrm{Ca}^{2+}$ extrusion out of the cytosol. $\mathrm{HS}$-elevated $\mathrm{Ca}^{2+}$ occurs from apoplast entry to the cytosol or nucleus (either diffused from the cytosol or released from nuclear $\mathrm{Ca}^{2+}$ reservoirs). The CaM responds to the elevation of $\left[\mathrm{Ca}^{2+}\right]_{\mathrm{cyt}}$ signature to modulate the activity of numerous target proteins. (a) and (c) The $\mathrm{Ca}^{2+} / \mathrm{CaM}$ complex interacts with the HS transcription factors (HSFs) and modulates either HSF DNA-binding or transcriptional activities. (b,d) The $\mathrm{Ca}^{2+} / \mathrm{CaM}$ complex regulates the activation of HSF by modulating the phosphorylation status. The regulation is achieved by CaM-binding protein kinase (PK) or CaM binding protein phosphatase (PP). (c,d) CaM recognizes a high frequency and magnitude of the cytosolic $\mathrm{Ca}^{2+}$ signature and is translocated into the nucleus for responding to the nuclear $\left[\mathrm{Ca}^{2+}\right]\left(\left[\mathrm{Ca}^{2+}\right]_{n u c}\right)$ to bind or regulate the status of $\mathrm{HSF}$ phosphorylation in the nucleus. ACAs, autoinhibited $\mathrm{Ca}^{2+}$-ATPases; APC, adenine nucleotide/phosphate carrier; CAXs, $\mathrm{Ca}^{2+} / \mathrm{H}^{+}$cation antiporters; CNGC, cyclic nucleotide-gated ion channels; ECAs, ER-type calcium ATPases; GLR3.5, glutamate receptor 3.5; HMA1, heavy metal translocating P-type ATPase; LETM1; leucine zipper-EF-hand-containing transmembrane protein 1; MCU, mitochondrial calcium uniporter; TPC1, two-pore voltage-gated channel 1. 
two $\mathrm{Ca}^{2+}$-binding EF-hand motifs, and are considered to be multifunctional proteins. These proteins mostly act as general transducers of $\mathrm{Ca}^{2+}$-mediated signal cascades in eukaryotes submitted to various developmental and external stimuli. It was previously suggested that the transduction of environmental signals through CaM gene expression occurs in part by the elevation of $\left[\mathrm{Ca}^{2+}\right]_{\text {cyt }}$ levels (Braam and Davis, 1990). In orchard grass (Dactylis glomerata), DgHsp70, a homolog of cytosolic Hsp70, can bind to Arabidopsis CaM2 in the presence of $\mathrm{Ca}^{2+}$, whereas negative regulation of DgHsp70 decreases the ATPase and foldase activities via $\mathrm{Ca}^{2+} / \mathrm{CaM}$ binding (Cha et al., 2012). Furthermore, CaM is involved in HSR through the interaction with cytosolic maize (Zea mays) Hsp70 and sorghum (Sorghum bicolor) Hsp90 (Sun et al., 2000; Virdi et al., 2009). Increasing evidence indicates that CaM plays a crucial role in HS responses that lead to an elevation of $\left[\mathrm{Ca}^{2+}\right]_{\text {cyt }}$ signaling in various species (Gong et al., 1998; Liu et al., 2003, 2005; Wu et al., 2012). In wheat, CaM1-2 gene expression increases after $\mathrm{HS}$ at $37^{\circ} \mathrm{C}$ for $10 \mathrm{~min}$ and reaches its peak expression after $20 \mathrm{~min}$ HS exposure, as determined by northern analysis (Liu et al., 2003). In moss Physcomitrella patens, a $\left[\mathrm{Ca}^{2+}\right]_{\text {cyt }}$ elevation for $20 \mathrm{~min}$ was induced by HS via putative plasma membrane $\mathrm{Ca}^{2+}$-permeable channels (Saidi et al., 2009).

The elevated $\left[\mathrm{Ca}^{2+}\right]_{\text {cyt }}$ and CaM can directly modulate the DNA-binding activity of HSF to HSE, suggesting that they are involved in the expression of HSP genes through the regulation of HSF (Mosser et al., 1990; Li et al., 2004). Arabidopsis signal responsive 1-6 genes (SR1 to SR6), a $\mathrm{Ca}^{2+} / \mathrm{CaM}$-binding transcription factor, play roles in transcription activation through specific binding to a "CGCG box" (A/C/G)CGCG(G/T/C) in the promoter of genes that are involved in multiple signal transduction pathways, including HSR in plants (Yang and Poovaiah, 2002). CaM is involved in the modulation of transcription factors either through direct interaction with basic helix-loop-helix domains, or by the control of kinasemediated phosphorylation (Corneliussen et al., 1994; Corcoran and Means, 2001). In transgenic Arabidopsis, reporter GUS gene expression that is directed by the Hsp18.2 promoter was shown to be affected by $\mathrm{CaCl}_{2}$ and $\mathrm{CaM}$ antagonists (Liu et al., 2005). Arabidopsis CBK3, by phosphorylating HsfAla, enhances the binding activity to HSE, which promotes activation of HSF and HSP gene expression. Protein phosphatases, such as Arabidopsis PP7 are regulated by $\mathrm{CaM}$ that is dependent upon $\mathrm{Ca}^{2+}{ }_{-} \mathrm{CaM}$ binding, with the $p p 7$ mutation resulting in a reduction in acquired thermotolerance (Liu et al., 2007). We identified the rice OsCaM1-1, whose expression resembles the biphasic $\left[\mathrm{Ca}^{2+}\right]_{\text {cyt }}$ signal, and showed that overexpression of OsCaM1-1 induced the expression of Arabidopsis $\mathrm{Ca}^{2+} / \mathrm{HS}-$ related $C B K 3, P P 7, H S F$, and $H S P$ genes, and enhanced intrinsic thermotolerance in transgenic Arabidopsis ( $\mathrm{Wu}$ et al., 2012). Thus, OsCaM1-1 interprets the $\mathrm{Ca}^{2+}$ signal by the cytosolic $\mathrm{Ca}^{2+}$ concentration and by spatio-temporal $\mathrm{Ca}^{2+}$ parameters under HS. Furthermore, OsCaM1-1 contains potential miRNA168a and miRNA408 target sites, and both miRNAs harbor HSE, which may regulate transcription of these miRNAs in response to HS (Wu and Jinn, 2012).
Extracellular CaM was found to be involved in the initiation of pollen germination and tube growth by a heterotrimeric $\mathrm{G}$ protein in the cellular signaling process in lily (Lilium longiflorum) pollen (Ma et al., 1999). However, the functions of apoplastic CaM are still poorly understood in plant cells. In Cedrus deodara, apoplastic CaM maintained the tip-focused $\mathrm{Ca}^{2+}$ gradient and modulated the distribution of pectins during pollen tube growth (Wang et al., 2013). Apoplastic CaM contributed to $\mathrm{Ca}^{2+}$ homeostasis and cell wall remodeling during pollen development. Thus, the interaction between $\mathrm{Ca}^{2+}$ and apoplastic CaM may play a central role in the maintenance of $\mathrm{Ca}^{2+}$ gradients for cell-wall modeling. Arabidopsis NPG1 is a pollen-specific CaM-binding protein that interacts with PLLs, suggesting NPG1 may modify the pollen cell-wall through the interaction with PLLs (Shin et al., 2014). In addition, the largest releasable pool of $\mathrm{Ca}^{2+}$ is localized in the cell wall, reaching approximately $60-75 \%$ of the total tissue $\mathrm{Ca}^{2+}$ content (Demarty et al., 1984). Thus, apoplastic $\mathrm{Ca}^{2+}$ is essential for the control of cell integrity, cell wall cohesion, and plasma membrane permeability (Hirschi, 2004). It has been suggested that the increased $\left[\mathrm{Ca}^{2+}\right]_{c y t}$ elevation observed in transformed tobacco (Nicotiana tabacum) seedlings during HS arises from both apoplastic and cytosolic sources (Gong et al., 1998). Potato (Solanum tuberosum) plant growth under HS can persist at specific levels of $\mathrm{Ca}^{2+}$ in the root, providing insight into the mechanism by which the zone of root $\mathrm{Ca}^{2+}$ may modulate plant response to HS (Kleinhenz and Palta, 2002). In moss (Physcomitrella patens), a specific $\mathrm{Ca}^{2+}$-permeable channel in the plasma membrane, which regulated heat-inducible $\mathrm{Ca}^{2+}$ influx, thereby leading to HSR (Saidi et al., 2009). Moreover, the recovery of HS-released $\mathrm{Ca}^{2+}$ is essential for the acquisition of thermoprotection to mitigate lethal HS injury both in soybean and rice seedlings (Wu and Jinn, 2010; Wu et al., 2010).

Notably, the cleavage of apoplastic $\mathrm{Ca}^{2+}$ bridges between pectic carboxyl groups that were created by PMEs is considered to play an important role in cell wall remodeling because it retains cell integrity during $\mathrm{HS}$ by preventing the plasma membrane from tearing away from the cell wall ( Wu and Jinn, 2010; Wu et al., 2010). Thus, acquired thermotolerance is reported to critically depend on a preceding $\mathrm{Ca}^{2+}$ transient through the plasma membrane so that the HSR is regulated by the transient entry of apoplastic $\mathrm{Ca}^{2+}$ (Saidi et al., 2009; Wu and Jinn, 2012; Wu et al., 2012). Plant cells can monitor the functional integrity of cell walls, with the maintenance of cell wall integrity being an important process to relieve cellular stresses.

\section{CELL WALL REMODELING IN HEAT RESPONSE}

\section{Plant Cell Wall Basics}

The plant cell wall is a sophisticated structure formed by a complex mixture of cell wall polymers, such as polysacchariderich polymers, proteins, and pectin matrix that are assembled into a rigid, flexible, and dynamically organized network (Wu et al., 2017). Plant cell walls are multilayered and consist of three sections, including the middle lamella, primary cell wall, 
and secondary cell wall. The middle lamella is a pectin layer to cement the bond between two adjoining cells. The heterogeneous mixture of wall composition and thickness of the cell wall may deviate absolutely, depending on the environmental conditions. The primary wall surrounds growing cells or cells capable of cell growth; whereas the secondary wall is a highly specialized and thickened structure containing lignin, which undergoes irreversible changes in many fully developed cells. Cellulose is composed of repeating glucose residues connected through $\beta$-1,4-D-glucan ( $\beta$-glucan) bonds that are crossed intricately together to form microfibrils as the scaffold of the cell wall and interconnected by hemicelluloses (xyloglucans and xylans are the most abundant) and galacturonic-acid-rich pectins (Figure 3A).

Pectin, a highly structurally complex polysaccharide, constitutes the major component of primary cell walls for both monocots and dicots, and is important for both cellular adhesion and cell wall plasticity (Mohnen, 2008). For example, pectin makes up 35\% of the primary cell wall in dicots and non-grass monocots, $2-10 \%$ of grass primary walls, and up to $5 \%$ of wood tissues (Mohnen, 2008). The middle lamella, a pectinaceous interface, depends on the formation of intermolecular links between pectin molecules and is important for the adhesion of neighboring cells (Jarvis et al., 2003). Pectins also present in the junction zone between cells within secondary walls in the xylem and fiber cells of woody tissue (Mohnen, 2008). Fiber length of angiosperms is determined by intrusive tip growth, which requires dissolution of the middle lamella, wall loosening between adjacent cells to create space for tip growing (Goulao et al., 2011), and therefore, the modification of pectin may be occurring during secondary wall growth of trees. Generally, pectinaceous polysaccharides have been defined into five classes (Ridley et al., 2001; Caffall and Mohnen, 2009; Harholt et al., 2010), including HGA, RG-I and -II (RG-II), XGA, and AGA; presumably, these structural elements are linked covalently to form the pectin complex as shown in Figure 3B. It is generally believed that these pectic polysaccharides are covalently linked to, or tightly associated with other types of polysaccharides, since chemical treatments or digestion by pectin-degrading enzymes are required to isolate HGA, RG-I, and RG-II from each other and from cell walls (Nakamura et al., 2002; Coenen et al., 2007). The results support that a model of pectic polymers, HGA, RG-I, and RG-II are linked together during synthesis (Caffall and Mohnen, 2009). For instance, the HGA backbone can be hydrolyzed by PG to produce monomeric, dimeric, or oligomeric fragments; however, HGA, RG-I, and RG-II polysaccharides failed to resolve independently by size exclusion chromatography prior to fragmentation by PG digestion (York et al., 1996). Furthermore, the stretches of $\alpha$ - $(1,4)$-linked GalA of soybean soluble polysaccharides were found flanked by RG-I fragments, providing evidence that HGA and RG-I are directly connected through backbone residues (Nakamura et al., 2002). Similarly, it has been suggested that HGA is linked to xyloglucan through fragments of XGA that were not readily solubilized from walls unless treated with PG (Talmadge et al., 1973). Therefore, the backbone of HGA is covalently linked to RG-I and RG-II. It is also hypothesized to be crosslinked to xyloglucan or possibly other wall polymers in muro. In particular, HGA is a major component of pectin and has a conformational flexibility that can be influenced by growth, development, and environmental cues (Willats et al., 2001). HGA consists of a linear $\alpha$-1,4-linked $\mathrm{D}-$ GalA homopolymer, which is the most abundant pectin-rich polysaccharide, constituting $65 \%$ of the total pectin. A critical feature of HGA that influences its properties is the methylesterification at C6-carboxyl and acetylation at $\mathrm{C} 2$ or $\mathrm{C} 3$ position by specific HGA-modifying enzymes, which belong to large multigenic families in all sequenced species (Gou et al., 2012; Sénéchal et al., 2014).

Owing to the characteristics of pectic matter which form hydrophilic colloids, it has been stated that the primary cell wall is plastic and soft. This component is crucial for cell growth and expansion, and is thought to contribute to cell wall structural integrity, cell adhesion, and signal transduction (Ochoa-Villarreal et al., 2012). In addition, the depolymerization of cellulose and hemicellulose, along with pectin, is particularly abundant and dynamic during plant development and stress responses in terms of modifying cell-wall polysaccharides. Consequently, enzymatic cleavage of the cross-linking polysaccharides by a set of cell wall-related enzymes including $\beta$-glucosidase, XET/XTH, and PME etc., which are believed to play a role in modulating cell wall plasticity, apparently mediate cell-wall integrity during plant development and stress responses (Figure 3C). The details are described below.

\section{Revealing the Mechanism of Cell Wall Integrity Maintenance in Response to Abiotic Stresses}

It has been proposed that plants are able to respond to a spectrum of abiotic stress conditions due to modifications in cell-wall composition and structure to perform their respective functions for the maintenance of cell-wall integrity. However, our understanding of the mechanisms of stress-induced changes in wall composition and structure is still limited. Some cell wallrelated genes have been shown to contribute directly to alter cell-wall composition to maintain cell-wall integrity under abiotic stress. Abiotic stress modified cell-wall constituents by CesA enzymes which alter cellulose biosynthesis (Wang et al., 2016), for instance, AtCesA8/IRX1, which encodes a subunit of a CesA complex to constitute part of the cell wall, plays an important role in drought and osmotic stress responses in Arabidopsis (Chen et al., 2005). Arabidopsis SOS6 encodes a CesA-like protein (CSLD5) which has an important role in response to osmotic stress by regulating stress-induced ROS accumulation in plant cell walls (Zhu et al., 2010). In barley (Hordeum vulgare), a mutation in the HvCslF6 gene that causes the loss of $(1,3 ; 1,4)$ $\beta$-D-glucan reducing mixed-linkage glucan in primary cell wall yields mutants increasingly susceptible to chilling (Taketa et al., 2012). In leaves of tomato, $\beta$-glucosidase, which is responsible for degrading cellulose to free glucose molecules, is involved in the heat-stress response (Edreva et al., 2000). Additionally, $\beta$-glucosidase is likely involved in developing drought-tolerant wheat seedlings (cultivar Hong Mang Mai) by differentially changing cell-wall polysaccharides to favor drought tolerance (Konno et al., 2008). 
A

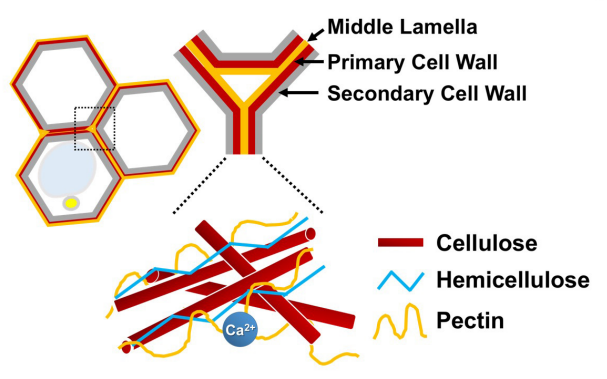

\section{Primary Cell Wall Constituents}

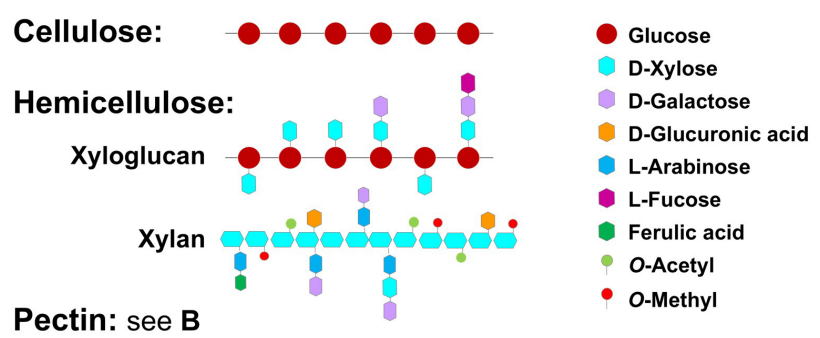

B

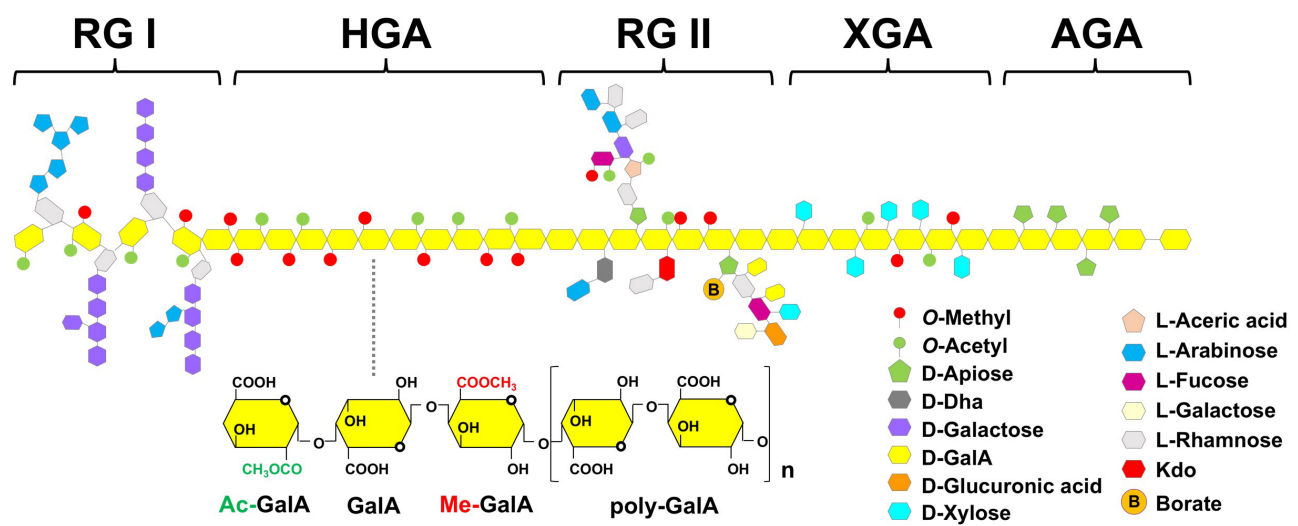

C
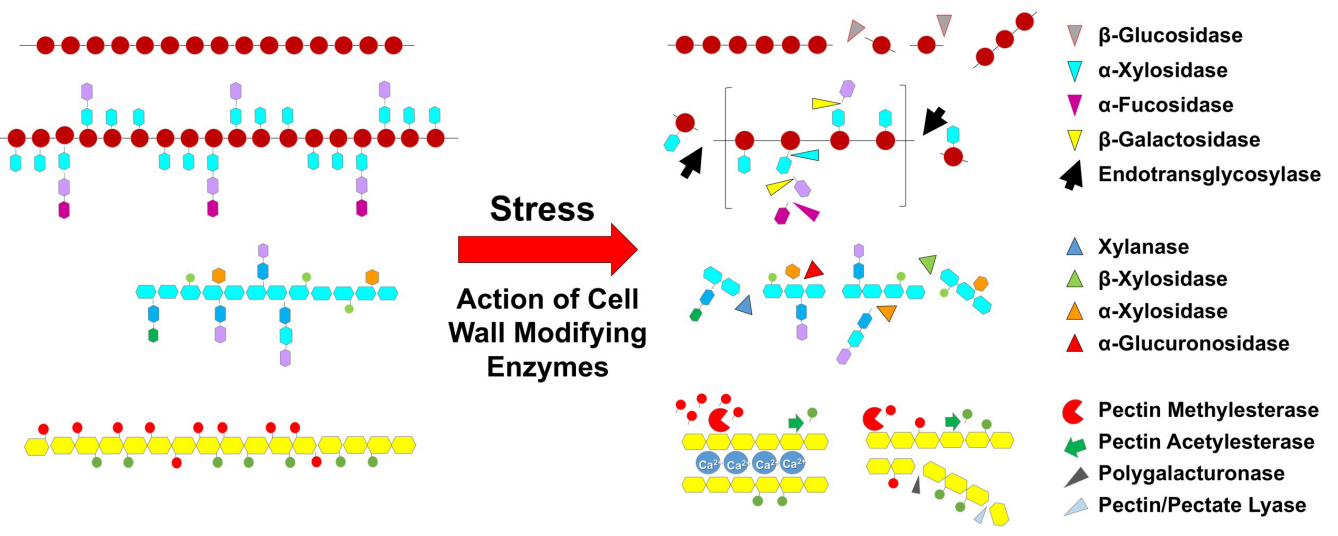

FIGURE 3 | Cell wall composition and enzymatic modification in response to heat. (A) The cell wall is a complex structure that is composed of cellulose and non-cellulosic neutral polysaccharides embedded in a pectin matrix. Pectins are located in the middle lamella and primary and secondary cell wall. Major primary cell wall are constituted of cellulose microfibrils (multiple chains of $\beta$-glucose with $\beta-1,4$ glycosidic bonds) which are cross-linked to hemicelluloses and to pectin. Xyloglucan is a major hemicellulose molecule that is composed of $\beta-1,4$-linked glucose residues with $\alpha-1,6$-linked xylosyl side chains. In turn, these side chains can be decorated with either galactose, or fucose residues to create a complex pattern of branches. Xylan consists a backbone of $\beta$-1,4-linked xylose (Xyl) residues that can be substituted with glucuronic acid and/or arabinose. Additional substitutions such as acetyl and methyl groups can be also presented. And (B) pectins are highly complex class of polysaccharides that comprise galacturonic acid-rich, consisting of five major classes, namely: homogalacturonan (HGA), rhamnogalacturonan I (RG-I), rhamnogalacturonan II (RG-II), xylogalacturonan (XGA), and apiogalacturonan (AGA) form a structurally diverse glue which provides stiffness or flexibility relying on the chemical modification. (C) Based on the action of hydrolysis and substrate specificity, the degradation of cellulose is cleaved by $\beta$-glucosidase into two molecules of glucose; for breaking down hemicellulose, xyloglucan endotransglycosylase/hydrolase (XTH), and expansin proteins (not shown) associated with disassembly of cellulose and xyloglucan matrix may play a role in the cell wall remodeling in different aspects of plant development and stress responses. Xylanase is responsible for degrading xylan by cleaving $\beta-1,4$ xylose linkages in the backbone. $\beta$-xylosidases cleave xylose from the non-reducing end of the xylan chain, and glucuronidases cleave the $\alpha-1,2$ linked glucuronic acid, and $\alpha$-arabinosidases cleave the $\alpha-1,2$ and $\alpha-1,3$ linked arabinose from the backbone. Pectinolytic enzymes such as PME, PAE, PG, PL, and Arabinanase by hydrolysis of pectic substances, are important for cell wall remodeling. The HGA, a polysaccharide of $\alpha-1,4$-linked galacturonic acid (GalA) residues, is the predominant form of pectin. A critical feature of HGA that influences its properties is the methyl-esterification and acetylation of specific carbons on GalA during synthesis of the backbone. HGA is de-methylesterified by the activity of PME, which results in random and contiguous patterns of free carboxylic residues. De-methyl-esterification randomly releases protons, which become a target for pectin-degrading enzymes such as PG, which act by hydrolyzing the $\alpha-1,4$ link between GalA. The contiguous de-methylesterified HGA binds with $\mathrm{Ca}^{2+}$ to induce gel formation, which can rigidify the cell wall. 
In coffee, arabinose and galactose contents increased, whereas mannose, glucose, uronic acid, rhamnose, and fucose contents decreased after HS (Lima et al., 2013). The desiccated plant Myrothamnus flabellifolius had lower amounts of arabinoxylans than those in the hydrated plant, due to the increased association between cell-wall polymers under stress (Moore et al., 2006). Thus, the chemical profile and structural cellwall polymers can be modified under HS. XET/XTH and EXP family members are involved in cell wall loosening and, therefore, in cell expansion for growth and development, as well as in the regulation of the plant responses under abiotic stress (Rose et al., 2002; Cosgrove, 2015). The overexpression of Capsicum annuum XTH3 in tomato showed that increased salt tolerance involved cell-wall flexibility for alleviating stress effects (Choi et al., 2011). In maize, some cell wall-related genes were up-regulated under salinity stress, including $Z m X E T 1$, ZmEXPA1, ZmEXPA3, ZmEXPA5, ZmEXPB1, and ZmEXPB2, to hydrolyze and rejoin xyloglucan molecules during cellwall extension ( $\mathrm{Li}$ et al., 2014). When Arabidopsis plants were exposed to boron toxicity, the expression of genes that encode CesA (CESA1, CESA4, CESA6, and CESA8), and CesAlike CSLB5, EXPs (EXPA5, EXP8, and EXPA14) were reduced, while PMEs (PME2 and PME41) showed a different expression pattern under boron stress and/or 24-epibrassinolide treatment (İşkil and Surgun-Acar, 2018). Heat-tolerant, thermal Agrostis scabra, AsEXP1 was strongly induced by exposure to HS, is associated with thermotolerant grass germplasm (Xu et al., 2007). Overexpression of a Kentucky bluegrass (Poa pratensis) PpEXP1 in tobacco exhibited a lesser extent of structural damage to cells resulted in enhanced HS tolerance. Thus, the EXP family may play more extensive and divergent effects on cell-wall integrity during stress responses. On the other hand, Arabidopsis HOT2 encodes a CTL1 that is essential for tolerance to salt stress by preventing $\mathrm{Na}^{+}$overaccumulation (Kwon et al., 2006). In Chinese cabbage (Brassica rapa), several genes encoding $\mathrm{XTH}$ proteins, $\beta$-glucosidase, CesA, EXP, extensin, glycosyl transferase, pectin esterase, and xylosidase, are up-regulated up to two-threefold following non-lethal temperature treatment at $37^{\circ} \mathrm{C}$, which enables plants to survive a subsequent lethal temperature (Yang K. A. et al., 2006). Thus, these results provided evidence that cell wall-related proteins or enzymes are required for the cell-wall modifications involved in thermotolerance acquisition.

Recent studies have described that ROS and peroxidases are key players which initially cross-link phenolic compounds and extensins, causing cell-wall stiffening under drought stress (Tenhaken, 2014). In addition, $\mathrm{OH}$ radicals, which are able to cleave sugar bonds in polysaccharides, cause loosening of the cell wall similar to the action of EXPs or xyloglucan modifying enzymes (Renew et al., 2005). In the review by Houston et al. (2016), a broader consideration was made of multiple cell wall-related genes appearing to respond to a given stimulus, and a defined set of stress-responsive transcription factors involved in transcriptional regulation. However, a specific target for cell-wall modifications due to different stress responses has to be explored in detail, especially in distinct species.

\section{Enzymatic Modification of Cell Wall Structure and Integrity}

It has been reported that HGA-type pectins play crucial roles in mediating the modification of cell wall mechanical properties and controlling turgor-induced plant morphogenesis through the action of pectinolytic enzymes (Levesque-Tremblay et al., 2015; Ali and Traas, 2016). In plants, pectinolytic enzymes or pectinases, which act by hydrolysis of pectic substances through the reactions of depolymerization (hydrolases and lyases) and deesterification (esterases), comprise a heterogeneous group of enzymes, including PMEs, PAEs, PGs, and PLs (Figure 3C). The acetyl- and methyl-esterifications of pectins represent the key parameters for the regulation of cell wall mechanical properties. HGA chains can be deacetylated in muro by PAE, with the resulting acetylester change dynamically impacting plant growth and development. It has been demonstrated that the deacetylation of pectin can lower the hydrophobicity of the polysaccharide backbone to increase pectin solubility in water (Rombouts and Thibault, 1986). Thus, PAEs are a crucial structural factor can protect polysaccharides against enzymatic digestion (Liners et al., 1994; Chen and Mort, 1996; Bonnin et al., 2003). Black cottonwood (Populus trichocarpa) that overexpress PtPAE1 exhibit disturbed pollen tube elongation and severe male sterility; however, PtPAE1-mediated deacetylation has been shown to lower the digestibility of pectin (Gou et al., 2012). Following the identification of the Arabidopsis PAE family, it was found that paes and pae 9 mutants led to $~ 20 \%$ increase in acetate accumulation in cell walls leading to the reduction in inflorescence growth (de Souza et al., 2014). Arabidopsis acetylation 2 (rwa2) mutation, which displayed a $20 \%$ reduction in cell-wall acetylation, was observed to increased resistance to Botrytis cinerea (Manabe et al., 2011). When Medicago truncatula was grown in a $\mathrm{CO}_{2}$ enriched atmosphere, $P A E$ genes were induced in response to aluminum stress and were associated with aluminum resistance (Chandran et al., 2008). In addition, data retrieved from the eFP Browser ${ }^{1}$ showed that Arabidopsis PAE2 and PAE4 were induced in response to osmotic and salt stress (Philippe et al., 2017).

Furthermore, the synthesis of HGA with a high methyl ester at C6 carboxyl residues occurs in the Golgi, which is then further exported into the cell wall in a highly methyl-esterified form of $70 \sim 80 \%$ methylesterification (Willats et al., 2001). The action of PME temporally and spatially regulates the fine control of the DM, i.e., the hydrolysis of the methylester bond at the C- 6 position of GalA in HGA, and is potentially involved in the regulation of cell wall architecture and determination of the methylesterification status of pectin. The increase of PME activity and DM are attributed to aluminum resistance in the root transition zone in pea (Pisum sativum) (Li X. et al., 2016). A limited number of investigations on the patterns of PME action in response to abiotic stresses suggest that this area is largely unknown. Thus, in subsequent discussion we focus on the function of PME to alter cell wall properties through the modification of different wall components, which plays

\footnotetext{
${ }^{1}$ http://bar.utoronto.ca/efp/cgi-bin/efpWeb.cgi
} 
an important role in the response to adverse environments, especially to heat exposure.

\section{Functions of Pectin Methylesterase}

Pectin methylesterases (EC 3.1.1.11), which belong to class 8 (CE8) of the carbohydrate esterases (CAZy website ${ }^{2}$ ) (Cantarel et al., 2009), and whose activity is regulated by PMEIs, modify the DM of pectins (Pelloux et al., 2007). In the Arabidopsis genome, 66 ORFs have been annotated as putative $P M E$ genes that are distinctively expressed (Louvet et al., 2006); furthermore, 89 and 80 PME ORFs correspond to the protein-coding genes in the poplar (Populus spp.) and Asiatic cotton (Gossypium arboreum) database, respectively (Geisler-Lee et al., 2006; Li W. et al., 2016). Conversely, fewer $P M E$ genes, as represented by 43 putative ORFs, were found in rice (O. sativa subsp. Japonica cv.; Jeong et al., 2015) compared to those of dicots, which may be related to the differences in the structure of the respective cell wall, such as less methyl esterified HGA in grass species (Vogel, 2008; Burton et al., 2010).

Depending on PME structure, Arabidopsis PMEs are frequently organized with an N-terminal extension of PRE and PRO sequence. PMEs can be classified into types I and II based on their presence or absence of the PRO domain. Type I is characterized by the presence of the $\mathrm{N}$-terminal PRO region, which show homology with PMEI domains, whereas type II is characterized by the absence of the PRO region (Figure 4A). The export of PME to the cell wall via the PRE domain, which can be mediated by a signal peptide or a transmembrane domain (TM or signal anchor), is required for protein targeting (Beigi et al., 2015). The PRO-region is required for correct targeting of the cell wall and supports an autoinhibitory activity of enzymes necessary for secretion of the mature PME to the apoplast (Giovane et al., 2004; Bosch et al., 2005). Type-II PME without the PRO-region and with five or six introns, has a similar structure to that of phytopathogenic organisms, such as fungi and bacteria (Pelloux et al., 2007). The localization of tobacco type-I PME, NtPPME1, was shown using a full-length product fused with GFP that is specifically expressed in the cell wall of pollen, whereas NtPPME1 lacking the PRO-region was maintained in the cytoplasm, suggesting that the PRO-region of NtPPME could assist the correct targeting of the mature PME (Bosch et al., 2005). The TM domain of tobacco PME Q9LEBO assists in the transport of PME to the cell surface and its export to the cell wall; however, the PRO-region of Q9LEBO does not affect targeting to the cell wall (Dorokhov et al., 2006).

\section{Actions of Pectin Methylesterase}

Pectin methylesterases function in de-esterification of the methylated carboxyl group $\left(\mathrm{COOCH}_{3}\right)$ of pectin to form elastic pectins and accompany $\mathrm{MeOH}$ generation during division and maturation of the plant cell (Komarova et al., 2014). Three modes of action of mature PMEs on polysaccharides have been proposed: single-chain, multiple-chain, and multipleattack mechanisms (Aragunde et al., 2018). In the single-chain mechanism, the activity of PME converts all substrate sites

${ }^{2}$ http://www.cazy.org on the polymeric chain. In the multiple-chain mechanism, PME catalyzes one reaction and then dissociates from the substrate, whereas PME catalyzes many cycles of reaction before the enzyme-polysaccharide complex dissociates in the multiple-attack mechanism (Beigi et al., 2015; Aragunde et al., 2018). Both single-chain and multiple-attack mechanisms have been proposed in plant and bacterial PMEs as these produce contiguous regions of GalAs (Christensen et al., 1998). Conversely, the random attack of fungal PMEs has been reported to be a multiple-chain mechanism (Duvetter et al., 2006).

During cell wall formation, HGA is de-methylesterified by the activity of PME, which results in contiguous and random patterns of free carboxylic residues. The contiguous demethylesterification of PME (by single-chain or multipleattack mechanism) leads to large amounts of demethylesterified GalA, the negatively charged chains of which can bind to $\mathrm{Ca}^{2+}$ to promote the formation of "egg box" structures and play a significant role in the structural rigidity of the cell wall. Their enzymatic activity can be modulated by different optimal $\mathrm{pH}$ values to further shift the mode of action to random demethylesterification (Hocq et al., 2017). Random demethylesterification (as a multiple-chain mechanism) releases protons that become a target for pectin-degrading enzymes such as PG (EC 3.2.1.15), which act by hydrolyzing the $\alpha$ 1,4 link between GalA. PG acts co-operatively with PME to disassemble the pectin polymer networks and contribute to cell wall weakening (Micheli, 2001). This observation has been confirmed by the combination of PME and PG activity causing an increased opening of stomatal aperture in both maize and Asiatic dayflower (Commelina communis) (Jones et al., 2005). However, incubation of PG alone did not show the effect on stomata opening, indicating that the methylesterified HGA is crucial for guard cell wall movement (Jones et al., 2005). Under salt stress, the increased demethylesterified pectins mediated by PME activity tend to crosslink with the $\mathrm{Ca}^{2+}$, leading to solidification of the cell wall and decreased growth (Uddin et al., 2013). Hence, the degree of pectin methyl-esterification affects $\mathrm{Ca}^{2+}$ cross-linking and pectate gel formation, which has dramatic consequences on cell wall texture and mechanical properties, thereby regulating cellular growth, cell shape, and defense reactions in plants (Pelloux et al., 2007).

In addition, the activity of PME is closely regulated by its endogenous inhibitor proteins, PMEIs, during plant development and growth (Micheli, 2001; Giovane et al., 2004). The additional PRO domain in type-I PME genes shares similarities with the PMEI domain of PMEI genes (Pelloux et al., 2007). PMEIs belong to plant invertase inhibitorrelated proteins, and as inhibitors, they play an important role in the regulation of metabolic enzymes (Koch, 1996). A transgenic Arabidopsis that constitutively expresses AtPMEI1 or AtPMEI-2 demonstrates a significant reduction in PME activity and increased levels of pectin methylesterification (Lionetti et al., 2012). Overexpression of a novel AtPMEI has a direct, profound effect on the activity of PME. Furthermore, increased PMEI accumulation significantly improved plant resistance to the fungal pathogens Botrytis cinerea, Bipolaris sorokiniana, and Fusarium graminearum (Lionetti et al., 2007; 
A

Type I
Type II

B

\section{Plant Development Shoot Apical Meristem e.g. PME5}

Pollen: e.g. QRT1, PME4/VGDH1 VGD1, PPME1, PME5, PME21, PME23, PME37, PME50

Inflorescence Stem e.g. PME35

Seed Mucilage e.g. PME6, PME58

\section{Embryo Morphology} e.g. PME6

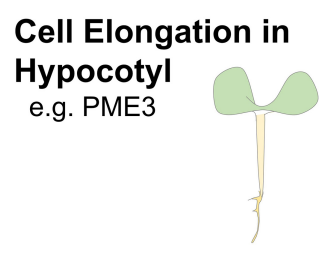

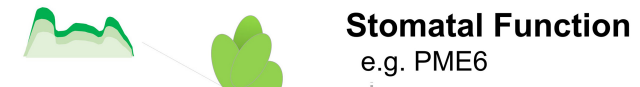

e.g. PME6

\section{Root Development} e.g. PME17

FIGURE 4 | Structural motif and function of pectin methylesterase (PME). (A) Types I and II PMEs contain a conserved PME domain, as the active part of the proteins. Type I includes the N-terminal extension of the PRE-PRO region, with the PRE domain containing a signal peptide (SP) or a transmembrane domain (TM) that is required for PME targeting to the cell wall. The N-terminal PRO region shows homology with pectin methylesterase inhibitors (PMEI), whereas type II is characterized by the absence of the PRO region. (B) Deficiency in specific PME genes reveals multiple roles of PME that have been linked to alteration of plant growth development and the response of plant defenses and abiotic stresses, respectively; related references are indicated in Table 1.

Volpi et al., 2011). The pepper (Capsicum annuum) CaPMEI gene, when overexpressed in Arabidopsis, enhances tolerance to Pseudomonas syringae pv. tomato, mannitol, and methyl viologen (An et al., 2008). In addition, the overexpression of PMEI limits the movement of tobamovirus (tobacco mosaic virus) in tobacco and Arabidopsis, and reduces plant susceptibility to the virus (Lionetti et al., 2014). Arabidopsis PME3 and PMEI7 were shown to have overlapping expression patterns in the etiolated hypocotyls when undergoing HGA methylesterification during plant development (Sénéchal et al., 2015). Overexpression of Arabidopsis PME5 and PMEI3 resulted in softer and harder shoot apical meristem cell walls, respectively (Peaucelle et al., 2011). Thus, the regulation of PMEI genes in the function of PME has a connection with plant development, defense, and stress response including wounding, drought, and oxidative and osmotic stresses (Greiner et al., 1998; An et al., 2008).

\section{Physiological Roles of Pectin Methylesterase}

Pectin methylesterases play an important role in both pectin remodeling and disassembly of the cell wall, and, therefore are involved in many physiological processes, including microsporogenesis, pollen germination, tube growth, pollen separation, seed germination, root development, stem elongation, polarity of leaf growth, and fruit softening during post-harvest fruit ripening (Wen et al., 1999; Pilling et al., 2000; Jiang et al., 2005; Francis et al., 2006; Tian et al., 2006). Moreover, over the past few years, several loss-of-function phenotypes of Arabidopsis $P M E$ have been described, as shown in Figure 4B and Table 1.

QUARTET1 (QRT1) assists in the liberation of pollen grains from tetrads during floral development (Francis et al., 2006). VANGUARD1 (VGD1) and PPME1 (PME9) promote pollen tube 
TABLE 1 | Identification of specific Pectin methylesterase (PME) genes reveals multiple roles of PME in Arabidopsis.

\begin{tabular}{|c|c|c|c|}
\hline Genes & AGI code & Functions & Reference \\
\hline PME3 & At3g14310 & $\begin{array}{l}\text { Cell elongation in hypocotyls. Involved } \\
\text { in plant immune responses. }\end{array}$ & Hewezi et al., 2008 \\
\hline PME5 & At5g47500 & $\begin{array}{l}\text { Involved in shoot apical meristem cell } \\
\text { walls. }\end{array}$ & Peaucelle et al., 2011 \\
\hline PME6 & At1g23200 & $\begin{array}{l}\text { Embryo development. Stomata } \\
\text { function. }\end{array}$ & $\begin{array}{l}\text { Levesque-Tremblay et al., 2015; } \\
\text { Amsbury et al., } 2016\end{array}$ \\
\hline PME7 & At1g02810 & $\begin{array}{l}\text { It may be involved in basal } \\
\text { thermotolerance. }\end{array}$ & Huang et al., 2017 \\
\hline PME17 & At2g45220 & $\begin{array}{l}\text { Involved root development and in } \\
\text { response to various stresses. }\end{array}$ & Sénéchal et al., 2014 \\
\hline PME21 & At3g05610 & $\begin{array}{l}\text { Expressed in dry and imbibed pollen } \\
\text { grains. }\end{array}$ & Mollet et al., 2013; Leroux et al., 2015 \\
\hline PME23 & At3g06830 & $\begin{array}{l}\text { Expressed in dry and imbibed pollen } \\
\text { grains. }\end{array}$ & Mollet et al., 2013 \\
\hline PME34 & At3g49220 & Involved in thermotolerance. & Huang et al., 2017 \\
\hline PME35 & At3g59010 & $\begin{array}{l}\text { Provides mechanical support to the } \\
\text { Arabidopsis stem. }\end{array}$ & Hongo et al., 2012 \\
\hline PME37 & At3g62170 & $\begin{array}{l}\text { Expressed in dry and imbibed pollen } \\
\text { grains. }\end{array}$ & Mollet et al., 2013; Leroux et al., 2015 \\
\hline PME41 & At4g02330 & $\begin{array}{l}\text { It may serve as one of the mechanisms } \\
\text { that BR participates in chilling tolerance } \\
\text { of plants. }\end{array}$ & Qu et al., 2011 \\
\hline PME48 & At5g07410 & Involved in pollen grain germination. & Mollet et al., 2013; Leroux et al., 2015 \\
\hline PME50 & At5g07430 & $\begin{array}{l}\text { Expressed in dry and imbibed pollen } \\
\text { grains. }\end{array}$ & Mollet et al., 2013; Leroux et al., 2015 \\
\hline PME58 & At5g49180 & Seed mucilage. & Turbant et al., 2016 \\
\hline PPME1 & At1g69940 & $\begin{array}{l}\text { Promote pollen tube growth. Involved in } \\
\text { plant immune responses. }\end{array}$ & Tian et al., 2006 \\
\hline QUARTET1 (QRT1) & At5g55590 & $\begin{array}{l}\text { Assisting in the liberation of pollen } \\
\text { grains from tetrads during floral } \\
\text { development. }\end{array}$ & Francis et al., 2006 \\
\hline VANGUARD1 (VGD1) & At2g47040 & Promote pollen tube growth. & Jiang et al., 2005 \\
\hline VGDH1 & At2g47030 & $\begin{array}{l}\text { VGD1 homolog. Expressed in dry } \\
\text { pollen grains. }\end{array}$ & $\begin{array}{l}\text { Jiang et al., 2005; Mollet et al., 2013; } \\
\text { Leroux et al., } 2015\end{array}$ \\
\hline
\end{tabular}

growth (Jiang et al., 2005; Tian et al., 2006). PME-mediated demethylesterification is thought to be required to render HGA susceptible to PG-mediated degradation; for example, PME QRT1 potentially acts in tandem with PG QRT3 to degrade de-methylesterified HGA in pollen mother cell primary walls (Rhee et al., 2003; Francis et al., 2006). AtPME35 is responsible for the demethylesterification of pectins and is involved in regulating the mechanical strength of the supporting tissue in Arabidopsis inflorescence stems (Hongo et al., 2012). AtPME6 is abundant during mucilage secretion, acting on embryo morphology and mucilage extrusion, both of which are involved in embryo development (Levesque-Tremblay et al., 2015). In addition, AtPME58 is specifically expressed in mucilage secretory cells and plays a role in mucilage structure and organization (Turbant et al., 2016). PMEs also act as positive regulators in the control of cell elongation in dark-growth Arabidopsis hypocotyls (Pelletier et al., 2010). AtPME17 was highly coexpressed with and processed by a subtilisin-type serine protease AtSBT3.5 to release a mature apoplastic PME isoform that was involved in root development and in response to various stresses (Sénéchal et al., 2014). Pectin content, PME activity, and pectin demethylesterification are also involved in $\mathrm{H}_{2} \mathrm{O}_{2}$-induced cell expansion and in determining the root diameter of rice root tips (Xiong et al., 2015).

Additionally, the DM of HGA settled by PME constitutes an important decisive factor of the biological activity of OG-related signaling and the formation of $\mathrm{MeOH}$, leading to the elicitation of plant defense responses (Osorio et al., 2008). The higher degree of pectin methylesterification is less susceptible to hydrolysis by fungal endo-PG, and, therefore, highly methylesterified pectin can trigger plant resistance to pathogenic fungi (Lionetti et al., 2012). Several studies have reported that PME interaction with a virus-encoded MP is required for tobamovirus, turnip vein clearing virus, and cauliflower mosaic virus infection, mediating cell-to-cell movement of the virus through the plasmodesmata (Chen et al., 2000). AtPME3 interacts with the cellulose binding protein of the cyst nematode Heterodera schachtii and enhances the susceptibility of the plant to nematodes (Hewezi et al., 2008). Furthermore, AtPME3 acts as a susceptibility factor and is necessary for the initial colonization by necrotrophic pathogens B. cinerea and Pectobacterium carotovorum (Raiola et al., 2011). Moreover, PME-mediated pectin methyl de-esterification may 
influence the mediated release of pectin-derived compounds, which in turn elicits a defense response. Thus, the specific effect of PME in the pattern of pectin methylesterification plays a determinant role in plant immunity (Bethke et al., 2014). Overall, the study of $P M E$ genes revealed a considerable compatibility and differential control of regulatory pathways in plants.

In addition, some studies have described for the importance of pectin in secondary cell wall formation and modification. Pectinassociated $\beta$-1,4-galactans are detected in the secondary walls of tension and compression wood (Mellerowicz and Gorshkova, 2012). The occurrence of the pectin RG-II in the most primitive extant vascular plant groups (e.g., Pteridophytes, Lycophytes, and Bryophytes), is correlated with the upright growth of developed lignified secondary walls in vascular plants (Matsunaga et al., 2004). Additional evidence provided a clearer link between pectin modification and secondary wall formation. The expression of PMEs are involved in the expanding wood cells of poplar (Siedlecka et al., 2008), and in the stem, phloem, and xylem of Eucalyptus globulus (Goulao et al., 2011). Arabidopsis mutant lacking PME35 has been shown reduced the mechanical integrity in their stem interfascicular fibers (Hongo et al., 2012). Hence, pectin plays a role in the early stages of secondary wall deposition and has a fundamental role in secondary wall structure and function (Xiao and Anderson, 2013). However, the ability of cells to adapt to environmental changes through the regulation of PME-mediated modification in secondary cell wall for wall integrity maintenance remains a major challenge.

\section{Pectin Methyl Esterase Activity in Heat Responses}

To date, numerous studies have revealed that PME participates in the regulation of plant development by affecting the mechanical properties of the plant cell walls; however, little is known regarding the role of PME in abiotic stresses. The effects of temperature stress on the cell wall may be revealed at various levels such as cell wall architecture and composition. It has been shown that pectin contents are related to temperature-dependent modifications, and that the DM of pectins is also involved in temperature responses (Solecka et al., 2008; Wu et al., 2010; Lima et al., 2013; Bilska-Kos et al., 2017; Huang et al., 2017).

Available data support the idea that cell wall-modifying enzymes are involved in temperature stress responses. For example, in winter oil-seed rape, the cold temperaturedependent pectin modification through the regulation of pectin methylesterification degree causes a retardation in leaf expansion that is correlated with the development of cold acclimation and fungus resistance (Solecka et al., 2008). In the leaves of chillingsensitive CM109 maize (Z. mays spp. indentata, dent), low temperatures of $\sim 14^{\circ} \mathrm{C} / 12^{\circ} \mathrm{C}$ (day/night) result in a reduction of pectin contents and PME activity, especially after prolonged treatment for $28 \mathrm{~h}$ and 7 days (Bilska-Kos et al., 2017). High temperatures of $35-65^{\circ} \mathrm{C}$ cause an activation of PME activity and the formation of $\mathrm{MeOH}$ in the intact tissue of green bean and tomato (Anthon and Barrett, 2006). In winter oilseed rape, HS-induces a nearly 10-fold reduction in PME35 (EV193389) gene expression ( $\mathrm{Yu}$ et al., 2014). In tomato pollen, HsfA2 is an important coactivator of HsfAla during HSR; in addition, in developing anthers of $A 2 A S$ transgenic plants with suppressed HsfA2 level, approximately $25 \%$ of the genes have function codes assigned for cell wall-modifying enzymes (including several $P M E, P A E$, and $P L$ ) under non-stress conditions. It has been suggested that cell wall-related genes might be directly regulated by HsfA2 (Fragkostefanakis et al., 2016). Thus, cell wall-related genes might be regulated by HS-associated gene expression in HSR. The demethylesterification rate of PME activity was increased substantially with increasing temperature, although the mechanism for temperature activation is less understood.

\section{Pectin Methylesterase Effects on Cellular Calcium Levels}

Polysaccharides and pectin present as a $\mathrm{Ca}^{2+}$-pectate gel are embedded in the primary-cell-wall matrix, providing an enormous $\mathrm{Ca}^{2+}$ reservoir. Pectin contains largely demethylesterified HGA sequences cross-linked through $\mathrm{Ca}^{2+}$ bridges to form egg-box structures, which are responsible for maintaining the integrity of the pectic network (Jarvis et al., 2003). The distribution of $\mathrm{Ca}^{2+}$ at the cell wall is mainly the result of a plethora of binding sites for $\mathrm{Ca}^{2+}$ in the cell wall, as well as the carefully regulated transport of $\mathrm{Ca}^{2+}$ into the cytoplasm (Han et al., 2003). Elevated temperature may cause a loss of cell membrane integrity, which allows $\mathrm{Ca}^{2+}$ leakage out from the cells into the cell wall to activate PME activity (Anthon and Barrett, 2006). It is possible that, at elevated temperatures, some changes may occur in the PME enzyme that converts it to a different or more active form or that its activity may be increased by the presence of $\mathrm{Ca}^{2+}$ and other cations. In previous studies, we verified that fine-tuning of an apoplastic $\mathrm{Ca}^{2+}$ mechanism was associated with PME activity on the pectin methylesteri?cation status by immunolocalization analyses of $\mathrm{Ca}^{2+}$-demethylated HGA during HSR and EGTA chelator treatment (Wu et al., 2010). The removal of apoplastic $\mathrm{Ca}^{2+}$ might participate in HS signaling to induce HS protein expression and cell-wall remodeling to retain plasma membrane integrity, prevent leakage of cellular content and confer thermoprotection ( $\mathrm{Wu}$ and Jinn, 2010). The blossom-end rot (BER) is a $\mathrm{Ca}^{2+}$-related physiological disorder that occurs in tomato fruit. It has been shown that a reduced level of PME expression and activity directly determine a correlation with changes in cellular $\mathrm{Ca}^{2+}$ partitioning and distribution in fruits, leading to fruit susceptibility to BER development (de Freitas et al., 2012). The effect of PME expression and activity on the amount of esterified pectins and $\mathrm{Ca}^{2+}$ bound to the cell wall is an important factor for plant development and stress responses. Thus, the tight control of the DM of pectin and the formation of $\mathrm{Ca}^{2+}$ cross-linkage appears to play a major role in plant growth and act as a regulator in response to heat.

The action of PME and the level of $\mathrm{Ca}^{2+}$ availability within the apoplasm has a direct impact on cell wall strength and expansion (Conn et al., 2011). Because the $\mathrm{Ca}^{2+}$ binding to uronic acids is easy to exchange for $\mathrm{H}^{+}$(Sentenac and Grignon, 1981), this reaction may be involved in the acid-induced extension of the cell wall. Therefore, the carboxyl groups of pectin likely interact 
with the charged $\mathrm{H}^{+}$atom that functions to acidify and loosen the cell wall to reduce injury. The cell corners, which contribute to cell adhesion via $\mathrm{Ca}^{2+}$ cross-linking, bear greater tension and support the conductivity of mechanical stresses throughout the plant tissue (Ryden et al., 2003). Cleavage of the $\mathrm{Ca}^{2+}$ bridges between pectic carboxyl groups in the cell wall is important for cell-wall remodeling during stresses. This suggests that the cell wall regulates the level of $\mathrm{Ca}^{2+}$ concentration to make the cell more "relaxed," thereby increasing the capability to avoid the plasma membrane from detaching from the cell wall. The extra $\mathrm{Ca}^{2+}$ is mobilized into the cytoplasm through $\mathrm{Ca}^{2+}$ channels that were opened by depolarization. The extracellular influx of $\mathrm{Ca}^{2+}$ is governed by changes in the ion binding properties within the cell wall rather than movements across the plasma membrane (Holdaway-Clarke et al., 1997). Moreover, pectin gel strength increases with increasing $\mathrm{Ca}^{2+}$ concentration but decreases with increased temperature and acidity (Lootens et al., 2003). Thus, the cell wall needs to eliminate $\mathrm{Ca}^{2+}$ and maintain low-level apoplastic $\mathrm{Ca}^{2+}$ during HS, resulting in increasing $\mathrm{Ca}^{2+}$ levels in the cytoplasm for regulating intracellular levels in response to HS (Wu et al., 2010).

Because $\mathrm{MeOH}$ is a product of PME action, it might serve as a volatile signal in the protection of photosynthetic machinery from photo-inhibition; stimulating the growth of C3 plants and the signaling of plant-herbivore interactions for plant defense mechanisms (Nonomura and Benson, 1992; Frenkel et al., 1998; Von Dahl et al., 2006). Furthermore, $\mathrm{MeOH}$ activates various patterns of gene expression that are involved in detoxification and signaling pathways, including the induction of HSP genes (Downie et al., 2004). The OGs, as pectin fragments related to PME activities that act as elicitors to stimulate the production of ROS, plasma membrane depolarization, and increased inositol triphosphate and $\left[\mathrm{Ca}^{2+}\right]_{\mathrm{cyt}}$, have been widely reported in plants (Moscatiello et al., 2006). It has been shown that the extracellular domain of WAK1, which functions as a potential sensor of cell wall signaling by directly binding to the $\mathrm{Ca}^{2+}$ crosslinking pectin-derived OGs, is involved in cell growth, cell expansion, and disease resistance (Wagner and Kohorn, 2001; Decreux and Messiaen, 2005; Kohorn et al., 2006; Li et al., 2009). The heat-activated PME participates in pectin remodeling, which in turn keeps cells from separating and maintains plasmamembrane integrity, prevents cellular leakage, and coordinates with HS signaling to confer thermoprotection ( $\mathrm{Wu}$ and Jinn, 2010). Together, these findings suggest that homeostasis of the apoplastic $\left[\mathrm{Ca}^{2+}\right]$ through the regulation of PME activity during HSR might have a pronounced effect on the development of heat tolerance by preventing cellular leakage through $\mathrm{Ca}^{2+}$-pectate remodeling in the cell wall.

\section{Guard Cell Wall Remodeling in Heat Responses}

Guard cells comprise a highly developed system that is used to determine and characterize the mechanism of the early signal transduction pathway in plants. In particular, they are involved in gas exchange between the interior of the plant and the external environment through the regulation of successive openings and closures of the stomatal pore. Guard cells perceive a multitude of endogenous and environmental stimuli including hormonal stimuli, light, humidity, $\mathrm{CO}_{2}$ concentration, drought, and temperature to trigger cellular responses resulting in stomatal opening or closure (Kim et al., 2010; Wu et al., 2017). High temperature increases the risk of heat damage and water shortage to plants. In response to elevated temperatures, transpiration occurs through the opening of stomatal apertures to facilitate cooling of the leaf surface through water evaporation (Figure 5A). In contrast, drought can cause stomatal closure and reduce transpiration rates; therefore, stomatal control is considered to be a short-term dynamic adaptation to avoid the reduction in leaf water potential (Osakabe et al., 2014).

Immunolocalization analyses of Arabidopsis leaf sections indicate highly methylesterified and $\mathrm{Ca}^{2+}$ cross-linked deesterified HGA in mesophyll cells, whereas unesterified HGA constitutes the predominant form of pectin in guard-cell walls, leading the stomatal closure response (Amsbury et al., 2016). Arabidopsis PME6 and polygalacturonase involved in expansion

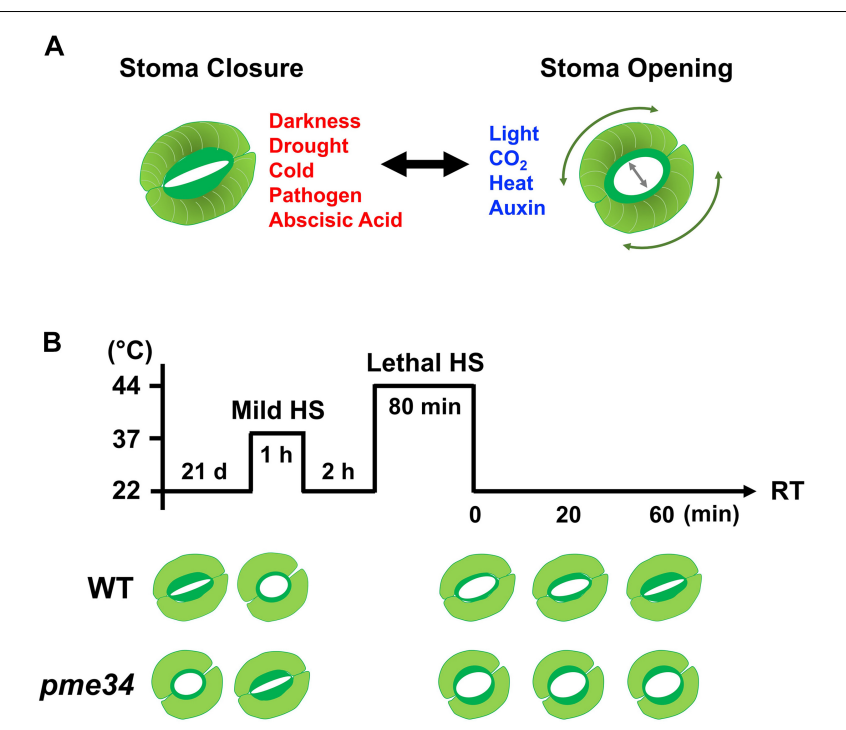

FIGURE 5 | Arabidopsis PME34 regulates the stomatal aperture under heat stress. (A) The inner wall of a guard cell is thicker and more elastic than the outer cell wall to facilitate the opening of the stomatal pore. The elastic property of the guard cell wall acts reversibly during stomatal opening and closing owing to differential thickening and the orientation of cellulose microfibrils (expressed in threads). The openings and closures of the stomata pore are strictly regulated by the integration of environmental stimuli and endogenous hormonal signals. (B) Comparison of elevated temperature stimulated-stomatal opening in wild-type (WT; Col) and pme34 mutant plants. Leaves (21-day-old) of WT and pme34 plants were treated with $37^{\circ} \mathrm{C}$-mild and $44^{\circ} \mathrm{C}$-lethal heat stress (LHS), respectively, as indicated. The pictogram shows the HS regime and the schematic diagram in the lower panel indicates the response of the stomatal aperture. Under normal condition, pme34 plants had a larger stomata aperture compared with that of WT plants. Under mild-HS treatment, the stomatal apertures in WT plants increased for aiding the dissipation of heat, whereas those of pme34 plants did not. Following the further $44^{\circ} \mathrm{C}$ LHS at recovery time (RT), stomatal apertures of pme34 were opened wider than those of WT plants, indicating greater water loss than that in WT plants. 
3 (PGX3) in the guard cells play an important role in response to stomatal opening/closure control (Amsbury et al., 2016; Rui et al., 2017). In a previous study, heat-exposed rice plants exhibited lower stomatal conductance until harvest, which can affect carbon balance, grain-filling processes, and yield production (Yang and Heilman, 1991). In C. communis, it has been shown that a $40^{\circ} \mathrm{C}$ HS for $5 \mathrm{~min}$ in roots could lead to a significant decrease in stomatal conductance, indicating that the communication between root and shoot is mediated by longdistance signaling (Yang S. et al., 2006). In Mimosa pudica, heat stimulation triggers rapid hydro-passive stomatal opening and subsequent stomatal closure that is concomitant with a loss of net $\mathrm{CO}_{2}$ uptake (Kaiser and Grams, 2006).

The highly specialized walls of guard cells enable them to undergo large and reversible deformation during the constriction of stomata (Wu et al., 2017). Therefore, it is possible that cell wall modification factors are involved in controlling stomata apertures. Recently, we found that Arabidopsis PME34 deficiency causes lower transpiration rates owing to an abnormal stomatal opening, leading to higher leaf temperatures and enhanced sensitivity to heat (Huang et al., 2017). The type-I PME gene PME34, which encodes a plasma membrane-localized and a cell wall deposited protein, functions during guard cell wall modification in response to heat. PME34 mutants have been shown to be hypersensitive to heat but independent of HSFmediated HSP gene transcriptional activation. The PME34 transcript was induced by $\mathrm{ABA}$ and highly expressed in guard cells, indicating that PME34 is associated with ABA-dependent stomatal movement in response to heat (Huang et al., 2017). High PME activity coincided with an increase in PG activity in pme34 plants, degrading pectin more easily, and further influencing the ability of guard cell walls to be modified in response to heat. This may support the idea proposed by $\mathrm{Wu}$ and Jinn (2010), who suggested that different PME isoforms exhibit distinct action patterns and pectic substrate specificity in response to HS. As highly methylesterified pectins are less susceptible to the action of PG, HS might render the cell wall to be more acidic so that it could stimulate the random demethylesterification activity of PME and promote the action of PG on pectin cleavage, further influencing the structural characteristics of guard cell walls for stomatal movement. Notably, the absence of PME34 activity in guard cells may be complemented by other PMEs and an integration with PG action to bring about the wide opening of stomata pores (Figure 5B).

Thus, PME34 may have a role in crosslinking with pectic polymers in the cell wall to regulate the flexibility of guard cell walls (Huang et al., 2017; Wu et al., 2017). Although PME functions to remove the methylester group from HGA to prevent stomatal opening, loss of PME34 resulted in wider stomata under lethal heat treatment. This is consistent with the observation that during drought stress, pme6 mutants have a significantly cooler leaf temperature than the wild-type plants, as well as a more restricted response to ABA (Amsbury et al., 2016). The pme34 mutant displayed a defect in the control of stomatal movement with a concomitant increase in leaf temperature. It also showed a higher transpiration rate through the more widely open stomata, which was probably due to the altered pectin methylesterification status of the guard cell wall properties. Thus, PME34 functions in controlling stomatal movements and in regulating the flexibility of the guard cell wall, which is required for the heat response. The impact of loss of PME34 on stomatal aperture may be due to $\mathrm{Ca}^{2+}$ signaling or oligosaccharides released during cell-wall modification, or both, which requires further investigation ( $\mathrm{Wu}$ et al., 2017).

\section{CONCLUSION AND PROSPECTIVE}

Although fine-tuning of the methylesterification of pectin through the regulation of PME activity during plant growth is relatively well understood, very little is known about stressinduced alterations of cell-wall polymers with respect to PME activity. Analysis of the patterns of pectin methylesterification in pme mutants is important to distinguish the distinct roles of individual PME genes. The evidence from genetic and transgenic plants indicated that the modification of cell wall remodeling has a pronounced effect on stress tolerance. The adjustment of the cell wall through the activity of PME under abiotic stresses is a critical determinant of plant adaptation. The change in cell wall metabolism and cell wall-modifying enzyme activity in controlling cell wall plasticity is an important physiological mechanism of plants in response to heat. The stress effect on the architecture of cell wall remodeling by PME activity may depend on the plant species, genotype, and growth stage, and also rely on the intensity and timing of the stress. In addition, the specificity of PMEI toward different PME isoforms can directly modulate the endogenous PME activity during plant development and various stress responses. In particular, complex interaction between PMEs and their inhibitors appears to be involved in a complex metabolic network and the regulation of gene expression pathways during plant growth and development as well as in stress adaptation. The additional complexity of the interaction of PME with other cellwall proteins to render a load-bearing, yet extensible primary cell wall during stress, remains an elusive issue. Much remains to be elucidated as to how the cell wall senses and transduces the signals leading to stress-induced transcriptional machinery changes and the underlying cell-wall polysaccharide deposition and modification. The role of cell wall-related genes, such as WAKs, which directly bind pectin polymers and partially depend upon the DM of pectin, and polysaccharides, has been explored during various stages of plant development (Kohorn et al., 2009; Tucker et al., 2018). The qualitative and quantitative assessment of cell wall composition at the single cell level is also required (Tucker et al., 2018). In particular, we need to elucidate single-cell responses to certain environmental changes. For instance, in the root cells of Arabidopsis, transcriptional changes were found to be directly related to alternations of cell-wall composition (Somssich et al., 2016), indicating that transcript abundance is followed by associated cell-wall modifying enzymes and proteins. Further, it is required to establish a direct connection between pectin 
modification and secondary wall formation by identifying and determining the function of pectin-related genes. Consequently, PME-mediated deesterification could be a crucial mechanism for contributing the secondary wall growth of wood development. Likewise, the transcriptional regulation of pectin-modifying genes might be an important aspect of secondary cell wall formation attributed to both abiotic and microbial challenges. These insights provide a foundation for further research such as transcriptomics studies that may reveal details of the cell wall machinery and stress-responsive transcription factors to provide targets and strategies to facilitate plant adaptation to HS.

\section{REFERENCES}

Ali, O., and Traas, J. (2016). Force-driven polymerization and turgor-induced wall expansion. Trends Plant Sci. 21, 398-409. doi: 10.1016/j.tplants.2016.01.019

Amsbury, S., Hunt, L., Elhaddad, N., Baillie, A., Lundgren, M., Verhertbruggen, Y., et al. (2016). Stomatal function requires pectin de-methyl-esterification of the guard cell wall. Curr. Biol. 26, 2899-2906. doi: 10.1016/j.cub.2016.08.021

An, S. H., Sohn, K. H., Choi, H. W., Hwang, I. S., Lee, S. C., and Hwang, B. K. (2008). Pepper pectin methylesterase inhibitor protein CaPMEI1 is required for antifungal activity, basal disease resistance and abiotic stress tolerance. Planta 228, 61-78. doi: 10.1007/s00425-008-0719-z

Anthon, G. E., and Barrett, D. M. (2006). Characterization of the temperature activation of pectin methylesterase in green beans and tomatoes. J. Agric. Food Chem. 54, 204-211. doi: 10.1021/jf051877q

Aragunde, H., Biarnés, X., and Planas, A. (2018). Substrate recognition and specificity of chitin deacetylases and related family 4 carbohydrate esterases. Int. J. Mol. Sci. 19:412. doi: 10.3390/ijms19020412

Ballén-Taborda, C., Plata, G., Ayling, S., Rodríguez-Zapata, F., Lopez-Lavalle, L. A. B., Duitama, J., et al. (2013). Identification of cassava microRNAs under abiotic stress. Int. J. Genomics 2013:857986. doi: 10.1155/2013/857986

Bäurle, I. (2016). Plant heat adaptation: priming in response to heat stress. F1000Res. 5:694. doi: 10.12688/f1000research.7526.1

Beigi, T. M., Ngadi, M. O., Holman, D. B., and Chénier, M. R. (2015). Pectin methylesterases: a review. J. Bioprocess. Biotech. 5:227.

Bethke, G., Grundman, R. E., Sreekanta, S., Truman, W., Katagiri, F., and Glazebrook, J. (2014). Arabidopsis pectin methylesterases contribute to immunity against Pseudomonas syringae. Plant Physiol. 164, 1093-1107. doi: $10.1104 /$ pp.113.227637

Bharti, K., Von Koskull-Doring, P., Bharti, S., Kumar, P., Tintschl-Korbitzer, A., Treuter, E., et al. (2004). Tomato heat stress transcription factor HsfB1 represents a novel type of general transcription coactivator with a histone-like motif interacting with the plant CREB binding protein ortholog HAC1. Plant Cell 16, 1521-1535. doi: 10.1105/tpc.019927

Bilska-Kos, A., Solecka, D., Dziewulska, A., Ochodzki, P., Jończyk, M., Bilski, H., et al. (2017). Low temperature caused modifications in the arrangement of cell wall pectins due to changes of osmotic potential of cells of maize leaves ( $\mathrm{Zea}$ mays L.). Protoplasma 254, 713-724. doi: 10.1007/s00709-016-0982-y

Bonnin, E., Le Goff, A., Van Alebeek, G. W. M., Voragen, A. G. J., and Thibault, J. F. (2003). Mode of action of Fusarium moniliforme endopolygalacturonase towards acetylated pectin. Carbohydr. Polym. 52, 381-388. doi: 10.1016/S01448617(02)00332-6

Bosch, M., Cheung, A. Y., and Hepler, P. K. (2005). Pectin methylesterase, a regulator of pollen tube growth. Plant Physiol. 138, 1334-1346. doi: 10.1104/ pp.105.059865

Boyko, A., Blevins, T., Yao, Y., Golubov, A., Bilichak, A., Inytskyy, Y., et al. (2010). Transgenerational adaptation of Arabidopsis to stress requires DNA methylation and the function of dicer-like proteins. PLoS One 5:e9514. doi: 10.1371/journal.pone.0009514

Braam, J., and Davis, R. W. (1990). Rain-, wind-, and touch-induced expression of calmodulin and calmodulin-related genes in Arabidopsis. Cell 60, 357-364. doi: 10.1016/0092-8674(90)90587-5

\section{AUTHOR CONTRIBUTIONS}

$\mathrm{H}-\mathrm{CW}$ and T-LJ conceived and wrote the manuscript. VB contributed to the final version of the manuscript.

\section{FUNDING}

This work was supported by the National Taiwan University (Grant Nos. 101R892003-105R892003 and 106R891506) and by the Ministry of Science and Technology, Taiwan (Grant Nos. 1052311-B-002-033-MY3 and 107-2923-B-002-003-MY3) to T-LJ.

Burton, R. A., Gidley, M. J., and Fincher, G. B. (2010). Heterogeneity in the chemistry, structure and function of plant cell walls. Nat. Chem. Biol. 6:724. doi: $10.1038 /$ nchembio.439

Busch, W., Wunderlich, M., and Schöffl, F. (2005). Identification of novel heat shock factor-dependent genes and biochemical pathways in Arabidopsis thaliana. Plant J. 41, 1-14. doi: 10.1111/j.1365-313X.2004.02272.x

Caffall, K. H., and Mohnen, D. (2009). The structure, function, and biosynthesis of plant cell wall pectic polysaccharides. Carbohyd. Res. 344, 1879-1900. doi: 10.1016/j.carres.2009.05.021

Cantarel, B. L., Coutinho, P. M., Rancurel, C., Bernard, T., Lombard, V., and Henrissat, B. (2009). The carbohydrate-active EnZymes database (CAZy): an expert resource for glycogenomics. Nucleic Acids Res. 37, D233-D238. doi: 10.1093/nar/gkn663

Carvalho, C. P., Hayashi, A. H., Braga, M. R., and Nievola, C. C. (2013). Biochemical and anatomical responses related to the in vitro survival of the tropical bromeliad Nidularium minutum to low temperatures. Plant Physiol. Biochem. 71, 144-154. doi: 10.1016/j.plaphy.2013.07.005

Cavrak, V. V., Lettner, N., Jamge, S., Kosarewicz, A., Bayer, L. M., and Mittelsten Scheid, O. (2014). How a retrotransposon exploits the plant's heat stress response for its activation. PLoS Genet. 10:e1004115. doi: 10.1371/journal.pgen. 1004115

Cha, J. Y., Su'udi, M., Kim, W. Y., Kim, D. R., Kwak, Y. S., and Son, D. (2012). Functional characterization of orchardgrass cytosolic Hsp70 (DgHsp70) and the negative regulation by Ca2+/AtCaM2 binding. Plant Physiol. Biochem. 58, 29-36. doi: 10.1016/j.plaphy.2012.06.006

Chandran, D., Sharopova, N., Ivashuta, S., Gantt, J. S., VandenBosch, K. A., and Samac, D. A. (2008). Transcriptome profiling identified novel genes associated with aluminum toxicity, resistance and tolerance in Medicago truncatula. Planta 228, 151-166. doi: 10.1007/s00425-008-0726-0

Charng, Y. Y., Liu, H. C., Liu, N. Y., Chi, W. T., Wang, C. N., Chang, S. H., et al. (2007). A heat-inducible transcription factor, HsfA2, is required for extension of acquired thermotolerance in Arabidopsis. Plant Physiol. 143, 251-262. doi: 10.1104/pp.106.091322

Charng, Y. Y., Liu, H. C., Liu, N. Y., Hsu, F. C., and Ko, S. S. (2006). Arabidopsis Hsa32, a novel heat shock protein, is essential for acquired thermotolerance during long recovery after acclimation. Plant Physiol. 140, 1297-1305. doi: 10.1104/pp.105.074898

Chen, E. M. W., and Mort, A. J. (1996). Nature of sites hydrolyzable by endopolygalacturonase in partially-esterified homogalacturonans. Carbohydr. Polym. 29, 129-136. doi: 10.1016/0144-8617(96)00005-7

Chen, M. H., Sheng, J., Hind, G., Handa, A. K., and Citovsky, V. (2000). Interaction between the tobacco mosaic virus movement protein and host cell pectin methylesterases is required for viral cell-to-cell movement. EMBO J. 19, 913920. doi: 10.1093/emboj/19.5.913

Chen, Z., Hong, X. I., Zhang, H., Wang, Y., Li, X., Zhu, J. K., et al. (2005). Disruption of the cellulose synthase gene, AtCesA8/IRX1, enhances drought and osmotic stress tolerance in Arabidopsis. Plant J. 43, 273-283. doi: 10.1111/j. 1365-313X.2005.02452.x

Choi, J. Y., Seo, Y. S., Kim, S. J., Kim, W. T., and Shin, J. S. (2011). Constitutive expression of CaXTH3, a hot pepper xyloglucan endotransglucosylase/hydrolase, enhanced tolerance to salt and drought 
stresses without phenotypic defects in tomato plants (Solanum lycopersicum cv, Dotaerang). Plant Cell Rep. 30, 867-877.

Christensen, T. M., Nielsen, J. E., Kreiberg, J. D., Rasmussen, P., and Mikkelsen, J. D. (1998). Pectin methyl esterase from orange fruit: characterization and localization by in-situ hybridization and immunohistochemistry. Planta 206, 493-503. doi: 10.1007/s004250050426

Coenen, G. J., Bakx, E. J., Verhoef, R. P., Schols, H. A., and Voragen, A. G. J. (2007). Identification of the connecting linkage between homo- or xylogalacturonan and rhamnogalacturonan type I. Carbohydr. Polym. 70, 224-235. doi: 10.1016/ j.carbpol.2007.04.007

Conn, S. J., Gilliham, M., Athman, A., Schreiber, A. W., Baumann, U., Moller, I., et al. (2011). Cell-specific vacuolar calcium storage mediated by CAX1 regulates apoplastic calcium concentration, gas exchange, and plant productivity in Arabidopsis. Plant Cell 23, 240-257. doi: 10.1105/tpc.109.072769

Corcoran, E. E., and Means, A. R. (2001). Defining Ca2+/calmodulin-dependent protein kinase cascades in transcriptional regulation. J. Biol. Chem. 276, 29752978. doi: 10.1074/jbc.R000027200

Corneliussen, B., Holm, M., Waltersson, Y., Onions, J., Hallberg, B., Thornell, A., et al. (1994). Calcium/calmodulin inhibition of basic-helix-loop-helix transcription factor domains. Nature 368:760. doi: 10.1038/368760a0

Cosgrove, D. J. (2015). Plant expansins: diversity and interactions with plant cell walls. Curr. Opin. Plant Boil 25, 162-172. doi: 10.1016/j.pbi.2015.05.014

de Freitas, S. T., Handa, A. K., Wu, Q., Park, S., and Mitcham, E. J. (2012). Role of pectin methylesterases in cellular calcium distribution and blossom-end rot development in tomato fruit. Plant J. 71, 824-835. doi: 10.1111/j.1365-313X. 2012.05034.x

de Souza, A., Hull, P. A., Gille, S., and Pauly, M. (2014). Identification and functional characterization of the distinct plant pectin esterases PAE8 and PAE9 and their deletion mutants. Planta 240, 1123-1138. doi: 10.1007/s00425-0142139-6

Decreux, A., and Messiaen, J. (2005). Wall-associated kinase WAK1 interacts with cell wall pectins in a calcium-induced conformation. Plant Cell Physiol. 46, 268-278. doi: 10.1093/pcp/pci026

Demarty, M., Morvan, C., and Thellier, M. (1984). Calcium and the cell wall. Plant Cell Environ. 7, 441-448. doi: 10.1111/j.1365-3040.1984.tb01434.x

Demidchik, V., and Maathuis, F. J. M. (2007). Physiological roles of nonselective cation channels in plants: from salt stress to signalling and development. New Phytol. 175, 387-404. doi: 10.1111/j.1469-8137.2007.02128.x

Dodd, A. N., Kudla, J., and Sanders, D. (2010). The language of calcium signaling. Annu. Rev. Plant Biol. 61, 593-620. doi: 10.1146/annurev-arplant-070109104628

Dolmetsch, R. E., Lewis, R. S., Goodnow, C. C., and Healy, J. I. (1997). Differential activation of transcription factors induced by $\mathrm{Ca} 2+$ response amplitude and duration. Nature 386:855. doi: 10.1038/386855a0

Dorokhov, Y. L., Skurat, E. V., Frolova, O. Y., Gasanova, T. V., Ivanov, P. A., Ravin, N. V., et al. (2006). Role of the leader sequence in tobacco pectin methylesterase secretion. FEBS Lett. 580, 3329-3334. doi: 10.1016/j.febslet.2006. 04.090

Downie, A., Miyazaki, S., Bohnert, H., John, P., Coleman, J., Parry, M., et al. (2004). Expression profiling of the response of Arabidopsis thaliana to methanol stimulation. Phytochemistry 65, 2305-2316. doi: 10.1016/j.phytochem.2004.07. 006

Duvetter, T., Fraeye, I., Sila, D., Verlent, I., Smout, C., Hendrickx, M., et al. (2006). Mode of de-esterification of alkaline and acidic pectin methyl esterases at different pH conditions. J. Agric. Food Chem. 54, 7825-7831. doi: 10.1021/ jf060013h

Edreva, A., Sotirova, V., Georgieva, I. D., Stoimenova, E., Rodeva, R., and Bogatzevska, N. (2000). Differential expression of $\beta$-glucosidase in tomatostress stimuli systems. Acta Physiol. Plant. 22, 274-277. doi: 10.1007/s11738000-0031-4

Folsom, J. J., Begcy, K., Hao, X., Wang, D., and Walia, H. (2014). Rice fertilizationindependent endosperm 1 regulates seed size under heat stress by controlling early endosperm development. Plant Physiol. 165, 238-248. doi: 10.1104/pp. 113.232413

Fragkostefanakis, S., Mesihovic, A., Simm, S., Paupière, M. J., Hu, Y., Paul, P., et al. (2016). HsfA2 controls the activity of developmentally and stress-regulated heat stress protection mechanisms in tomato male reproductive tissues. Plant Physiol. 170, 2461-2477. doi: 10.1104/pp.15.01913
Francis, K. E., Lam, S. Y., and Copenhaver, G. P. (2006). Separation of Arabidopsis pollen tetrads is regulated by QUARTET1, a pectin methylesterase gene. Plant Physiol. 142, 1004-1013. doi: 10.1104/pp.106.085274

Frenkel, C., Peters, J. S., Tieman, D. M., Tiznado, M. E., and Handa, A. K. (1998). Pectin methylesterase regulates methanol and ethanol accumulation in ripening tomato (Lycopersicon esculentum) fruit. J. Biol. Chem. 273, 4293-4295. doi: 10.1074/jbc. 273.8 .4293

Fu, S., Meeley, R., and Scanlon, M. J. (2002). Empty pericarp2 encodes a negative regulator of the heat shock response and is required for maize embryogenesis. Plant Cell 14, 3119-3132. doi: 10.1105/tpc.006726

Geisler-Lee, J., Geisler, M., Coutinho, P. M., Segerman, B., Nishikubo, N., Takahashi, J., et al. (2006). Poplar carbohydrate-active enzymes, gene identification and expression analyses. Plant Physiol. 140, 946-962. doi: 10.1104/pp.105.072652

Giovane, A., Servillo, L., Balestrieri, C., Raiola, A., D’avino, R., Tamburrini, M., et al. (2004). Pectin methylesterase inhibitor. Biochim. Biophys. Acta 1696, 245-252. doi: 10.1016/j.bbapap.2003.08.011

Gong, M., Van Der Luit, A. H., Knight, M. R., and Trewavas, A. J. (1998). Heatshock-induced changes in intracellular $\mathrm{Ca} 2+$ level in tobacco seedlings in relation to thermotolerance. Plant Physiol. 116, 429-437. doi: 10.1104/pp.116. 1.429

Gou, J. Y., Miller, L. M., Hou, G., Yu, X. H., Chen, X. Y., and Liu, C. J. (2012). Acetylesterase-mediated deacetylation of pectin impairs cell elongation, pollen germination, and plant reproduction. Plant Cell 24, 50-65. doi: 10.1105/tpc.111. 092411

Goulao, L. F., Vieira-Silva, S., and Jackson, P. A. (2011). Association of hemicellulose- and pectin-modifying gene expression with Eucalyptus globulus secondary growth. Plant Physiol. Biochem. 49, 873-881. doi: 10.1016/j.plaphy. 2011.02.020

Greiner, S., Krausgrill, S., and Rausch, T. (1998). Cloning of a tobacco apoplasmic invertase inhibitor: proof of function of the recombinant protein and expression analysis during plant development. Plant Physiol. 116, 733-742. doi: 10.1104/ pp.116.2.733

Hahn, A., Bublak, D., Schleiff, E., and Scharf, K. D. (2011). Crosstalk between Hsp90 and Hsp70 chaperones and heat stress transcription factors in tomato. Plant Cell 23, 741-755. doi: 10.1105/tpc.110.076018

Han, S., Tang, R., Anderson, L. K., Woerner, T. E., and Pei, Z. M. (2003). A cell surface receptor mediates extracellular $\mathrm{Ca} 2+$ sensing in guard cells. Nature 425:196.

Harholt, J., Suttangkakul, A., and Vibe Scheller, H. (2010). Biosynthesis of pectin. Plant Physiol. 153, 384-395. doi: 10.1104/pp.110.156588

Hewezi, T., Howe, P., Maier, T. R., Hussey, R. S., Mitchum, M. G., Davis, E. L., et al. (2008). Cellulose binding protein from the parasitic nematode Heterodera schachtii interacts with Arabidopsis pectin methylesterase: cooperative cell wall modification during parasitism. Plant Cell 20, 3080-3093. doi: 10.1105/tpc.108. 063065

Hirschi, K. D. (2004). The calcium conundrum, both versatile nutrient and specific signal. Plant Physiol. 136, 2438-2442. doi: 10.1104/pp.104.046490

Hocq, L., Pelloux, J., and Lefebvre, V. (2017). Connecting homogalacturonan-type pectin remodeling to acid growth. Trends Plant Sci. 22, 20-29. doi: 10.1016/j. tplants.2016.10.009

Holdaway-Clarke, T. L., Feijo, J. A., Hackett, G. R., Kunkel, J. G., and Hepler, P. K. (1997). Pollen tube growth and the intracellular cytosolic calcium gradient oscillate in phase while extracellular calcium influx is delayed. Plant Cell 9, 1999-2010. doi: 10.1105/tpc.9.11.1999

Hongo, S., Sato, K., Yokoyama, R., and Nishitani, K. (2012). Demethylesterification of the primary wall by PECTIN METHYLESTERASE35 provides mechanical support to the Arabidopsis stem. Plant Cell 24, 2624-2634. doi: 10.1105/tpc.112. 099325

Houston, K., Tucker, M. R., Chowdhury, J., Shirley, N., and Little. (2016). The plant cell wall: a complex and dynamic structure as revealed by the responses of genes under stress conditions. Front. Plant Sci. 7:984. doi: 10.3389/fpls.2016. 00984

Hsu, S. F., Lai, H. C., and Jinn, T. L. (2010). Cytosol-localized heat shock factor-binding protein, AtHSBP, functions as a negative regulator of heat shock response by translocation to the nucleus and is required for seed development in Arabidopsis. Plant Physiol. 153, 773-784. doi: 10.1104/pp.109. 151225 
Huang, Y. C., Niu, C. Y., Yang, C. R., and Jinn, T. L. (2016). The heat stress factor HSFA6b connects ABA signaling and ABA-mediated heat responses. Plant Physiol. 172, 1182-1199. doi: 10.1104/pp.16.00860

Huang, Y. C., Wu, H. C., Wang, Y. D., Liu, C. H., Lin, C. C., Luo, D. L., et al. (2017). PECTIN METHYLESTERASE34 contributes to heat tolerance through its role in promoting stomatal movement. Plant Physiol. 174, 748-763. doi: 10.1104/pp.17.00335

Ikeda, M., Mitsuda, N., and Ohme-Takagi, M. (2011). Arabidopsis HsfB1 and $\mathrm{HsfB} 2 \mathrm{~b}$ act as repressors of the expression of heat-inducible Hsfs but positively regulate the acquired thermotolerance. Plant Physiol. 157, 1243-1254. doi: 10.1104/pp.111.179036

Imazu, H., and Sakurai, H. (2005). Saccharomyces cerevisiae heat shock transcription factor regulates cell wall remodeling in response to heat shock. Eukaryot. Cell 4, 1050-1056. doi: 10.1128/EC.4.6.1050-1056.2005

IPCC. (2012). "Managing the risks of extreme events and disasters to advance climate change adaptation," in A Special Report of Working Groups I and Ii of the Intergovernmental Panel on Climate Change, eds C. B Field, V. Barros, T. F. Stocker, D. Qin, D. J. Dokken, K. L. Ebi, et al. (Cambridge: Cambridge University Press).

İşkil, R., and Surgun-Acar, Y. (2018). Expression analysis of cell wall assembly and remodelling-related genes in Arabidopsis roots subjected to boron stress and brassinosteroid at different developmental stages. Acta Bot. Bras. 32, 546-554. doi: 10.1590/0102-33062018abb0023

Ito, H., Gaubert, H., Bucher, E., Mirouze, M., Vaillant, I., and Paszkowski, J. (2011). An siRNA pathway prevents transgenerational retrotransposition in plants subjected to stress. Nature 472, 115-119. doi: 10.1038/nature09861

Jarvis, M. C., Briggs, S. P. H., and Knox, J. P. (2003). Intercellular adhesion and cell separation in plants. Plant Cell Environ. 26, 977-989. doi: 10.1046/j.1365-3040. 2003.01034.x

Jeong, H. Y., Nguyen, H. P., and Lee, C. (2015). Genome-wide identification and expression analysis of rice pectin methylesterases: implication of functional roles of pectin modification in rice physiology. J. Plant Physiol. 183, 23-29. doi: 10.1016/j.jplph.2015.05.001

Jiang, L., Yang, S. L., Xie, L. F., Puah, C. S., Zhang, X. Q., Yang, W. C., et al. (2005). VANGUARD1 encodes a pectin methylesterase that enhances pollen tube growth in the Arabidopsis style and transmitting tract. Plant Cell 17, 584-596. doi: 10.1105/tpc.104.027631

Jones, L., Milne, J. L., Ashford, D., Mccann, M. C., and Mcqueen-Mason, S. J. (2005). A conserved functional role of pectic polymers in stomatal guard cells from a range of plant species. Planta 221, 255-264. doi: 10.1007/s00425-004$1432-1$

Kaiser, H., and Grams, T. E. E. (2006). Rapid hydropassive opening and subsequent active stomatal closure follow heat-induced electrical signals in Mimosa pudica. J. Exp. Bot. 57, 2087-2092. doi: 10.1093/jxb/erj165

Khraiwesh, B., Zhu, J. K., and Zhu, J. (2012). Role of miRNAs and siRNAs in biotic and abiotic stress responses of plants. Biochim. Biophys. Acta 1819, 137-148. doi: 10.1016/j.bbagrm.2011.05.001

Kim, M. C., Chung, W. S., Yun, D. J., and Cho, M. J. (2009). Calcium and calmodulin-mediated regulation of gene expression in plants. Mol. Plant 2, 13-21. doi: 10.1093/mp/ssn091

Kim, T. H., Böhmer, M., Hu, H., Nishimura, N., and Schroeder, J. I. (2010). Guard cell signal transduction network: advances in understanding abscisic acid, $\mathrm{CO}_{2}$, and Ca2+ signaling. Annu. Rev. Plant Biol. 61, 561-591. doi: 10.1146/annurevarplant-042809-112226

Kleinhenz, M. D., and Palta, J. P. (2002). Root zone calcium modulates the response of potato plants to heat stress. Physiol. Plant. 115, 111-118. doi: 10.1034/j.13993054.2002.1150113.x

Klis, F. M., Boorsma, A., and De Groot, P. W. J. (2006). Cell wall construction in Saccharomyces cerevisiae. Yeast 23, 185-202. doi: 10.1002/yea.1349

Koch, K. E. (1996). Carbohydrate-modulated gene expression in plants. Annu. Rev. Plant Physiol. Plant Mol. Biol. 47, 509-540. doi: 10.1146/annurev.arplant. 47.1.509

Kohorn, B. D., Johansen, S., Shishido, A., Todorova, T., Martinez, R., Defeo, E., et al. (2009). Pectin activation of MAP kinase and gene expression is WAK2 dependent. Plant J. 60, 974-982. doi: 10.1111/j.1365-313X.2009.04016.x

Kohorn, B. D., Kobayashi, M., Johansen, S., Riese, J., Huang, L. F., Koch, K., et al. (2006). An Arabidopsis cell wall-associated kinase required for invertase activity and cell growth. Plant J. 46, 307-316. doi: 10.1111/j.1365-313X.2006.02695.x
Komarova, T. V., Pozdyshev, D. V., Petrunia, I. V., Sheshukova, E. V., and Dorokhov, Y. L. (2014). Pectin methylesterase-generated methanol may be involved in tobacco leaf growth. Biochemisrt (Mosc.) 79, 102-110. doi: 10.1134/ S0006297914020035

Konno, H., Yamasaki, Yoshiki, Sugimoto, M., and Takeda, K. (2008). Differential changes in cell wall matrix polysaccharides and glycoside-hydrolyzing enzymes in developing wheat seedlings differing in drought tolerance. J. Plant Physiol. 165, 745-754. doi: 10.1016/j.jplph.2007.07.007

Kumar, S. V., and Wigge, P. A. (2010). H2A.Z-containing nucleosomes mediate the thermosensory response in Arabidopsis. Cell 140, 136-147. doi: 10.1016/j. cell.2009.11.006

Kwon, Y., Kim, S. H., Jung, M. S., Kim, M. S., Oh, J. E., Ju, H. W., et al. (2006). Arabidopsis hot2 encodes an endochitinase-like protein that is essential for tolerance to heat, salt and drought stresses. Plant J. 49, 184-193. doi: 10.1111/j. 1365-313X.2006.02950.x

Lämke, J., and Bäurle, I. (2017). Epigenetic and chromatin-based mechanisms in environmental stress adaptation and stress memory in plants. Genome Biol. 18:124. doi: 10.1186/s13059-017-1263-6

Larkindale, J., Hall, J. D., Knight, M. R., and Vierling, E. (2005). Heat stress phenotypes of Arabidopsis mutants implicate multiple signaling pathways in the acquisition of thermotolerance. Plant Physiol. 138, 882-897. doi: 10.1104/ pp. 105.062257

Larkindale, J., and Vierling, E. (2008). Core genome responses involved in acclimation to high temperature. Plant Physiol. 146, 748-761. doi: 10.1104/pp. 107.112060

Le Gall, H., Philippe, F., Domon, J. M., Gillet, F., Pelloux, J., and Rayon, C. (2015). Cell wall metabolism in response to abiotic stress. Plants (Basel) 4, 112-166. doi: 10.3390/plants4010112

Leroux, C., Bouton, S., Kiefer-Meyer, M.-C., Fabrice, T. N., Mareck, A., Guénin, S., et al. (2015). PECTIN METHYLESTERASE48 is involved in Arabidopsis pollen grain germination. Plant Physiol. 167, 367-380. doi: 10.1104/pp.114.250928

Levesque-Tremblay, G., Müller, K., Mansfield, S. D., and Haughn, G. W. (2015). HIGHLY METHYL ESTERIFIED SEEDS is a pectin methyl esterase involved in embryo development. Plant Physiol. 167, 725-737. doi: 10.1104/pp.114.255604

Li, B., Liu, H. T., Sun, D. Y., and Zhou, R. G. (2004). Ca2+ and calmodulin modulate DNA-binding activity of maize heat shock transcription factor in vitro. Plant Cell Physiol. 45, 627-634. doi: 10.1093/pcp/pch074

Li, H., Yan, S., Zhao, L., Tan, J., Zhang, Q., Gao, F., et al. (2014). Histone acetylation associated up-regulation of the cell wall related genes is involved in salt stress induced maize root swelling. BMC Plant Biol. 14:105. doi: 10.1186/1471-222914-105

Li, H., Zhou, S. Y., Zhao, W. S., Su, S. C., and Peng, Y. L. (2009). A novel wallassociated receptor-like protein kinase gene, OsWAK1, plays important roles in rice blast disease resistance. Plant Mol. Biol. 69:337. doi: 10.1007/s11103-0089430-5

Li, X., Li, Y., Qu, M., Xiao, H., Feng, Y., Liu, J., et al. (2016). Cell wall pectin and its methyl-esterification in transition zone determine $\mathrm{Al}$ resistance in cultivars of pea (Pisum sativum). Front. Plant Sci. 7:39. doi: 10.3389/fpls.2016.00039

Li, W., Shang, H., Ge, Q., Zou, C., Cai, J., Wang, D., et al. (2016). Genome-wide identification, phylogeny, and expression analysis of pectin methylesterases reveal their major role in cotton fiber development. BMC Genomics 17:1000. doi: 10.1186/s12864-016-3365-z

Lima, R. B., Dos Santos, T. B., Vieira, L. G., Ferrarese Mde, L., Ferrarese-Filho, O., Donatti, L., et al. (2013). Heat stress causes alterations in the cell-wall polymers and anatomy of coffee leaves (Coffea arabica L.). Carbohydr. Polym. 93, 135143. doi: 10.1016/j.carbpol.2012.05.015

Lin, J. S., Kuo, C. C., Yang, I. C., Tsai, W. A., Shen, Y. H., Lin, C. C., et al. (2018). MicroRNA160 modulates plant development and heat shock protein gene expression to mediate heat tolerance in Arabidopsis. Front. Plant Sci. 9:68. doi: $10.3389 /$ fpls.2018.00068

Lindquist, S., and Craig, E. A. (1988). The heat-shock proteins. Annu. Rev. Genet. 22, 631-677. doi: 10.1146/annurev.ge.22.120188.003215

Liners, F., Gaspar, T., and Van Cutsem, P. (1994). Acetyl- and methyl-esterification of pectins of friable and compact sugar-beet calli: consequences for intercellular adhesion. Planta 192, 545-556. doi: 10.1007/BF00203593

Lionetti, V., Cervone, F., and Bellincampi, D. (2012). Methyl esterification of pectin plays a role during plant-pathogen interactions and affects plant resistance to diseases. J. Plant Physiol. 169, 1623-1630. doi: 10.1016/j.jplph.2012.05.006 
Lionetti, V., Raiola, A., Camardella, L., Giovane, A., Obel, N., Pauly, M., et al. (2007). Overexpression of pectin methylesterase inhibitors in Arabidopsis restricts fungal infection by Botrytis cinerea. Plant Physiol. 143, 1871-1880. doi: 10.1104/pp.106.090803

Lionetti, V., Raiola, A., Cervone, F., and Bellincampi, D. (2014). Transgenic expression of pectin methylesterase inhibitors limits tobamovirus spread in tobacco and Arabidopsis. Mol. Plant Pathol. 15, 265-274. doi: 10.1111/mpp. 12090

Liu, H. C., Liao, H. T., and Charng, Y. Y. (2011). The role of class A1 heat shock factors (HSFA1s) in response to heat and other stresses in Arabidopsis. Plant Cell Environ. 34, 738-751. doi: 10.1111/j.1365-3040.2011.02278.x

Liu, H. T., Li, B., Shang, Z. L., Li, X. Z., Mu, R. L., Sun, D. Y., et al. (2003). Calmodulin is involved in heat shock signal transduction in wheat. Plant Physiol. 132, 1186-1195. doi: 10.1104/pp.102.018564

Liu, H. T., Li, G. L., Chang, H., Sun, D. Y., Zhou, R. G., and Li, B. (2007). Calmodulin-binding protein phosphatase PP7 is involved in thermotolerance in Arabidopsis. Plant Cell Environ. 30, 156-164. doi: 10.1111/j.1365-3040.2006. 01613.x

Liu, H. T., Sun, D. Y., and Zhou, R. G. (2005). Ca2+ and AtCaM3 are involved in the expression of heat shock protein gene in Arabidopsis. Plant Cell Environ. 28, 1276-1284. doi: 10.1111/j.1365-3040.2005.01365.x

Liu, J., Feng, L., Li, J., and He, Z. (2015). Genetic and epigenetic control of plant heat responses. Front. Plant Sci. 6:267. doi: 10.3389/fpls.2015. 00267

Lootens, D., Capel, F., Durand, D., Nicolai, T., Boulenguer, P., and Langendorff, V. (2003). Influence of $\mathrm{pH}$, Ca concentration, temperature and amidation on the gelation of low methoxyl pectin. Food Hydrocoll. 17, 237-244. doi: 10.1016/ S0268-005X(02)00056-5

Louvet, R., Cavel, E., Gutierrez, L., Guénin, S., Roger, D., Gillet, F., et al. (2006). Comprehensive expression profiling of the pectin methylesterase gene family during silique development in Arabidopsis thaliana. Planta 224, 782-791. doi: 10.1007/s00425-006-0261-9

Ma, L., Xu, X., Cui, S., and Sun, D. (1999). The presence of a heterotrimeric G protein and its role in signal transduction of extracellular calmodulin in pollen germination and tube growth. Plant Cell 11, 1351-1363. doi: 10.1105/tpc.11.7. 1351

Manabe, Y., Nafisi, M., Verhertbruggen, Y., Orfila, C., Gille, S., Rautengarten, C., et al. (2011). Loss-of-function mutation of REDUCED WALL ACETYLATION2 in Arabidopsis leads to reduced cell wall acetylation and increased resistance to Botrytis cinerea. Plant Physiol. 155, 1068-1078. doi: 10.1104/pp.110.168989

Matsunaga, T., Ishii, T., Matsumoto, S., Higuchi, M., Darvill, A., Albersheim, P., et al. (2004). Occurrence of the primary cell wall polysaccharide rhamnogalacturonan II in pteridophytes, lycophytes, and bryophytes. Implications for the evolution of vascular plants. Plant Physiol. 134, 339-351. doi: 10.1104/pp.103.030072

Mellerowicz, E. J., and Gorshkova, T. A. (2012). Tensional stress generation in gelatinous fibres: a review and possible mechanism based on cell-wall structure and composition. J. Exp. Bot. 63, 551-565. doi: 10.1093/jxb/err339

Micheli, F. (2001). Pectin methylesterases: cell wall enzymes with important roles in plant physiology. Trends Plant Sci. 6, 414-419. doi: 10.1016/S1360-1385(01) 02045-3

Min, L., Li, Y., Hu, Q., Zhu, L., Gao, W., Wu, Y., et al. (2014). Sugar and auxin signaling pathways respond to high-temperature stress during anther development as revealed by transcript profiling analysis in cotton. Plant Physiol. 164, 1293-1308. doi: 10.1104/pp.113.232314

Mittler, R., Finka, A., and Goloubinoff, P. (2012). How do plants feel the heat? Trends Biochem. Sci. 37, 118-125. doi: 10.1016/j.tibs.2011. 11.007

Mlynárová, L., Nap, J. P., and Bisseling, T. (2007). The SWI/SNF chromatinremodeling gene AtCHR12 mediates temporary growth arrest in Arabidopsis thaliana upon perceiving environmental stress. Plant J. 51, 874-885. doi: 10. 1111/j.1365-313X.2007.03185.x

Mohnen, D. (2008). Pectin structure and biosynthesis. Curr. Opin. Plant Biol. 11, 266-277. doi: 10.1016/j.pbi.2008.03.006

Mollet, J. -C., Leroux, C., Dardelle, F., and Lehner, A. (2013). Cell wall composition, biosynthesis and remodeling during pollen tube growth. Plants 2, 107-147. doi: 10.3390/plants2010107
Monroy, A. F., and Dhindsa, R. S. (1995). Low-temperature signal transduction: induction of cold acclimation-specific genes of alfalfa by calcium at 25 degrees C. Plant Cell 7, 321-331. doi: 10.2307/3869854

Moore, J. P., Nguema-Ona, E., Chevalier, L., Lindsey, G. G., Brandt, W. F., Lerouge, P., et al. (2006). Response of the leaf cell wall to desiccation in the resurrection plant Myrothamnus flabellifolius. Plant Physiol. 141, 651-662. doi: 10.1104/pp.106.077701

Morimoto, R. I. (2008). Proteotoxic stress and inducible chaperone networks in neurodegenerative disease and aging. Genes Dev. 22, 1427-1438. doi: 10.1101/ gad. 1657108

Moscatiello, R., Mariani, P., Sanders, D., and Maathuis, F. J. M. (2006). Transcriptional analysis of calcium-dependent and calcium-independent signalling pathways induced by oligogalacturonides. J. Exp. Bot. 57, 2847-2865. doi: $10.1093 /$ jxb/erl043

Mosser, D. D., Kotzbauer, P. T., Sarge, K. D., and Morimoto, R. I. (1990). In vitro activation of heat shock transcription factor DNA-binding by calcium and biochemical conditions that affect protein conformation. Proc. Natl. Acad. Sci. U.S.A. 87, 3748-3752. doi: 10.1073/pnas.87.10.3748

Nakamura, A., Furuta, H., Maeda, H., Takao, T., and Nagamatsu, Y. (2002). Structural studies by stepwise enzymatic degradation of the main backbone of soybean soluble polysaccharides consisting of galacturonan and rhamnogalacturonan. Biosci. Biotechnol. Biochem. 66, 1301-1313. doi: 10.1271/ bbb.66.1301

Nonomura, A. M., and Benson, A. A. (1992). The path of carbon in photosynthesis: improved crop yields with methanol. Proc. Natl. Acad. Sci. U.S.A. 89, 97949798. doi: 10.1073/pnas.89.20.9794

Ochoa-Villarreal, M., Aispuro-Hernández, E., Vargas-Arispuro, I., and MartínezTéllez, M. Á. (2012). "Plant cell wall polymers: function, structure and biological activity of their derivatives," in Polymerization, Chap. 4, ed. A. D. S. Gomes (Rijeka: InTech).

Ohama, N., Sato, H., Shinozaki, K., and Yamaguchi-Shinozaki, K. (2017). Transcriptional regulatory network of plant heat stress response. Trends. Plant Sci. 22, 53-65. doi: 10.1016/j.tplants.2016.08.015

Osakabe, Y., Osakabe, K., Shinozaki, K., and Tran, L. S. (2014). Response of plants to water stress. Front. Plant Sci. 5:86. doi: 10.3389/fpls.2014.00086

Osorio, S., Castillejo, C., Quesada, M. A., Medina-Escobar, N., Brownsey, G. J., Suau, R., et al. (2008). Partial demethylation of oligogalacturonides by pectin methyl esterase 1 is required for eliciting defence responses in wild strawberry (Fragaria vesca). Plant J. 54, 43-55. doi: 10.1111/j.1365-313X.2007.03398.x

Peaucelle, A., Braybrook, S. A., Le Guillou, L., Bron, E., Kuhlemeier, C., and Höfte, H. (2011). Pectin-induced changes in cell wall mechanics underlie organ initiation in Arabidopsis. Curr. Biol. 21, 1720-1726. doi: 10.1016/j.cub.2011. 08.057

Pelletier, S., Van Orden, J., Wolf, S., Vissenberg, K., Delacourt, J., Ndong, Y. A., et al. (2010). A role for pectin de-methylesterification in a developmentally regulated growth acceleration in dark-grown Arabidopsis hypocotyls. New Phytol. 188, 726-739. doi: 10.1111/j.1469-8137.2010.03409.x

Pelloux, J., Rustérucci, C., and Mellerowicz, E. J. (2007). New insights into pectin methylesterase structure and function. Trends Plant Sci. 12, 267-277. doi: 10.1016/j.tplants.2007.04.001

Philippe, F., Pelloux, P., and Rayon, C. (2017). Plant pectin acetylesterase structure and function: new insights from bioinformatic analysis. BMC Genomics 18:456. doi: 10.1186/s12864-017-3833-0

Pilling, J., Willmitzer, L., and Fisahn, J. (2000). Expression of a petunia inflata pectin methyl esterase in Solanum tuberosum L. enhances stem elongation and modifies cation distribution. Planta 210, 391-399. doi: 10.1007/PL00008147

Qu, T., Liu, R., Wang, W., An, L., Chen, T., Liu, G., et al. (2011). Brassinosteroids regulate pectin methylesterase activity and AtPME41 expression in Arabidopsis under chilling stress. Cryobiology 63, 111-117. doi: 10.1016/j.cryobiol.2011.07.003

Raiola, A., Lionetti, V., Elmaghraby, I., Immerzeel, P., Mellerowicz, E. J., Salvi, G., et al. (2011). Pectin methylesterase is induced in Arabidopsis upon infection and is necessary for a successful colonization by necrotrophic pathogens. Mol. Plant Microbe. Interact. 24, 432-440. doi: 10.1094/MPMI-07-10-0157

Rana, R. M., Dong, S. N., Tang, H. J., Ahmad, F., and Zhang, H. S. (2012). Functional analysis of OsHSBP1 and OsHSBP2 revealed their involvement in the heat shock response in rice (Oryza sativa L.). J. Exp. Bot. 63, 6003-6016. doi: $10.1093 /$ jxb/ers 245 
Renew, S., Heyno, E., Schopfer, P., and Liszkay, A. (2005). Sensitive detection and localization of hydroxyl radical production in cucumber roots and Arabidopsis seedlings by spin trapping electron paramagnetic resonance spectroscopy. Plant J. 44, 342-347. doi: 10.1111/j.1365-313X.2005.02528.x

Rhee, S. Y., Osborne, E., Poindexter, P. D., and Somerville, C. R. (2003). Microspore separation in the quartet 3 mutants of Arabidopsis is impaired by a defect in a developmentally regulated polygalacturonase required for pollen mother cell wall degradation. Plant Physiol. 133, 1170-1180. doi: 10.1104/pp.103.028266

Ridley, B. L., O’Neill, M. A., and Mohnen, D. (2001). Pectins: structure, biosynthesis, and oligogalacturonide-related signaling. Phytochemistry 57, 929 967. doi: 10.1016/S0031-9422(01)00113-3

Rombouts, F. M., and Thibault, J. F. (1986). Enzymatic and chemical degradation and the fine structure of pectins from sugar-beet pulp. Carbohydr. Res. 154, 189-203. doi: 10.1016/S0008-6215(00)90032-6

Rose, J. K. C., Braam, J., Fry, S. C., and Nishitani, K. (2002). The XTH family of enzymes involved in xyloglucan endotransglucosylation and endohydrolysis: current perspectives and a new unifying nomenclature. Plant Cell Physiol. 43, 1421-1435. doi: 10.1093/pcp/pcf171

Rui, Y., Xiao, C., Yi, H., Kandemir, B., Wang, J. Z., Puri, V. M., et al. (2017). POLYGALACTURONASE INVOLVED IN EXPANSION3 functions in seedling development, rosette growth, and stomatal dynamics in Arabidopsis thaliana. Plant Cell 29, 2413-2432. doi: 10.1105/tpc.17.00568

Ryden, P., Sugimoto-Shirasu, K., Smith, A. C., Findlay, K., Reiter, W. D., and Mccann, M. C. (2003). Tensile properties of Arabidopsis cell walls depend on both a xyloglucan cross-linked microfibrillar network and rhamnogalacturonan II-borate complexes. Plant Physiol. 132, 1033-1040. doi: 10.1104/pp.103.02 1873

Saidi, Y., Finka, A., Muriset, M., Bromberg, Z., Weiss, Y. G., Maathuis, F. J. M., et al. (2009). The heat shock response in moss plants is regulated by specific calciumpermeable channels in the plasma membrane. Plant Cell 21, 2829-2843. doi: $10.1105 /$ tpc. 108.065318

Sato, H., Mizoi, J., Tanaka, H., Maruyama, K., Qin, F., Osakabe, Y., et al. (2014). Arabidopsis DPB3-1, a DREB2A interactor, specifically enhances heat stressinduced gene expression by forming a heat stress-specific transcriptional complex with NF-Y subunits. Plant Cell 26, 4954-4973. doi: 10.1105/tpc.114. 132928

Satyal, S. H., Chen, D. Y., Fox, S. G., Kramer, J. M., and Morimoto, R. I. (1998). Negative regulation of the heat shock transcriptional response by HSBP1. Genes Dev. 12, 1962-1974. doi: 10.1101/gad.12.13.1962

Scharf, K. D., Rose, S., Zott, W., Schöffl, F., and Nover, L. (1990). Three tomato genes code for heat stress transcription factors with a region of remarkable homology to the DNA-binding domain of the yeast HSF. EMBO J. 9, 4495-4501. doi: 10.1002/j.1460-2075.1990.tb07900.x

Sénéchal, F., L'enfant, M., Domon, J. M., Rosiau, E., Crépeau, M. J., Surcouf, O., et al. (2015). Tuning of pectin methylesterification: pectin methylesterase inhibitor 7 modulates the processive activity of co-expressed pectin methylesterase 3 in a pH-dependent manner. J. Biol. Chem. 290, 2332023335. doi: 10.1074/jbc.M115.639534

Sénéchal, F., Wattier, C., Rustérucci, C., and Pelloux, J. (2014). Homogalacturonanmodifying enzymes: structure, expression, and roles in plants. J. Exp. Bot. 65, 5125-5160. doi: 10.1093/jxb/eru272

Sentenac, H., and Grignon, C. (1981). A model for predicting ionic equilibrium concentrations in cell walls. Plant Physiol. 68, 415-419. doi: 10.1104/pp.68.2.415

Shin, S. B., Golovkin, M., and Reddy, A. S. N. (2014). A pollen-specific calmodulinbinding protein, NPG1, interacts with putative pectate lyases. Sci. Rep. 4:5263. doi: 10.1038/srep05263

Siedlecka, A., Wiklund, S., Peronne, M. A., Micheli, F., Lesniewska, J., Sethson, I., et al. (2008). Pectin methyl esterase inhibits intrusive and symplastic cell growth in developing wood cells of Populus. Plant Physiol. 146, 554-565. doi: 10.1104/ pp.107.111963

Solecka, D., Żebrowski, J., and Kacperska, A. (2008). Are pectins involved in cold acclimation and de-acclimation of winter oil-seed rape plants? Ann. Bot. 101, 521-530. doi: 10.1093/aob/mcm 329

Somssich, M., Khan, G. A., and Persson, S. (2016). Cell wall heterogeneity in root development of Arabidopsis. Front. Plant Sci. 7:1242. doi: 10.3389/fpls.2016. 01242

Stief, A., Altmann, S., Hoffmann, K., Pant, B. D., Scheible, W. R., and Bäurle, I. (2014). Arabidopsis miR156 regulates tolerance to recurring environmental stress through SPL transcription factors. Plant Cell 26, 1792-1807. doi: 10.1105/ tpc.114.123851

Sun, X. T., Li, B., Zhou, G. M., Tang, W. Q., Bai, J., Sun, D. Y., et al. (2000). Binding of the maize cytosolic hsp70 to calmodulin, and identification of calmodulinbinding site in hsp70. Plant Cell Physiol. 41, 804-810. doi: 10.1093/pcp/41. 6.804

Taketa, S., Yuo, T., Tonooka, T., Tsumuraya, Y., Inagaki, Y., Haruyama, N., et al. (2012). Functional characterization of barley betaglucanless mutants demonstrates a unique role for CsIF6 in $(1,3 ; 1,4)-\beta$-D-glucan biosynthesis. J. Exp. Bot. 63, 381-392. doi: 10.1093/jxb/err285

Talmadge, K. W., Keegstra, K., Bauer, W. D., and Albersheim, P. (1973). The structure of plant cell walls: I. The macromolecular components of the walls of suspension-cultured sycamore cells with a detailed analysis of the pectic polysaccharides. Plant Physiol. 51, 158-173. doi: 10.1104/pp.51.1.158

Tenhaken, R. (2014). Cell wall remodeling under abiotic stress. Front. Plant Sci. 5:771. doi: 10.3389/fpls.2014.00771

Tian, G. W., Chen, M. H., Zaltsman, A., and Citovsky, V. (2006). Pollen-specific pectin methylesterase involved in pollen tube growth. Dev. Biol. 294, 83-91. doi: 10.1016/j.ydbio.2006.02.026

Tucker, M. R., Lou, H., Aubert, M. K., Wilkinson, L. G., Little, A., Houston, K., et al. (2018). Exploring the role of cell wall-related genes and polysaccharides during plant development. Plants 7:42. doi: 10.3390/plants7020042

Turbant, A., Fournet, F., Lequart, M., Zabijak, L., Pageau, K., Bouton, S., et al. (2016). PME58 plays a role in pectin distribution during seed coat mucilage extrusion through homogalacturonan modification. J. Exp. Bot. 67, 2177-2190. doi: 10.1093/jxb/erw025

Uddin, M. N., Hanstein, S., Leubner, R., and Schubert, S. (2013). Leaf cell-wall components as influenced in the first phase of salt stress in three maize (Zea mays L.) hybrids differing in salt resistance. J. Agron. Crop Sci. 199, 405-415. doi: $10.1111 /$ jac. 12031

Vierling, E. (1991). The roles of heat shock proteins in plants. Annu. Rev. Plant Physiol. Plant Mol. Biol. 42, 579-620. doi: 10.1146/annurev.pp.42.060191. 003051

Virdi, A. S., Thakur, A., Dutt, S., Kumar, S., and Singh, P. (2009). A sorghum 85 $\mathrm{kDa}$ heat stress-modulated protein shows calmodulin-binding properties and cross-reactivity to anti-Neurospora crassa Hsp 80 antibodies. FEBS Lett. 583, $767-770$.

Vogel, J. (2008). Unique aspects of the grass cell wall. Curr. Opin. Plant Biol. 11, 301-307. doi: 10.1016/j.febslet.2009.01.025

Volpi, C., Janni, M., Lionetti, V., Bellincampi, D., Favaron, F., and D’ovidio, R. (2011). The ectopic expression of a pectin methyl esterase inhibitor increases pectin methyl esterification and limits fungal diseases in wheat. Mol. Plant Microbe Interact. 24, 1012-1019. doi: 10.1016/j.pbi.2008.03.002

Von Dahl, C. C., Hävecker, M., Schlögl, R., and Baldwin, I. T. (2006). Caterpillarelicited methanol emission: a new signal in plant-herbivore interactions? Plant J. 46, 948-960. doi: 10.1094/MPMI-01-11-0021

Wagner, T. A., and Kohorn, B. D. (2001). Wall-associated kinases are expressed throughout plant development and are required for cell expansion. Plant Cell 13, 303-318. doi: 10.1111/j.1365-313X.2006.02760.x

Wang, L. C., Wu, J. R., Chang, W. L., Yeh, C. H., Ke, Y. T., Lu, C. A., et al. (2013). Arabidopsis HIT4 encodes a novel chromocentre-localized protein involved in the heat reactivation of transcriptionally silent loci and is essential for heat tolerance in plants. J. Exp. Bot. 64, 1689-1701. doi: 10.1105/tpc.13.2.303

Wang, T., McFarlane, H. E., and Persson, S. (2016). The impact of abiotic factors on cellulose synthesis. J. Exp. Bot. 67, 543-552. doi: 10.1093/jxb/ert030

Wen, F., Zhu, Y., and Hawes, M. C. (1999). Effect of pectin methylesterase gene expression on pea root development. Plant Cell 11, 1129-1140. doi: 10.1105/ tpc.11.6.1129

Willats, W. G., Orfila, C., Limberg, G., Buchholt, H. C., Van Alebeek, G. J., Voragen, A. G., et al. (2001). Modulation of the degree and pattern of methylesterification of pectic homogalacturonan in plant cell walls. Implications for pectin methyl esterase action, matrix properties, and cell adhesion. J. Biol. Chem. 276, 19404-19413. doi: 10.1074/jbc.M011242200

Wolf, S., Mouille, G., and Pelloux, J. (2009). Homogalacturonan methylesterification and plant development. Mol. Plant 2, 851-860. doi: 10.1093/mp/ ssp066

Wu, H. C., Hsu, S. F., Luo, D. L., Chen, S. J., Huang, W. D., Lur, H. S., et al. (2010). Recovery of heat shock-triggered released apoplastic $\mathrm{Ca} 2+$ accompanied by 
pectin methylesterase activity is required for thermotolerance in soybean seedlings. J. Exp. Bot. 61, 2843-2852. doi: 10.1093/jxb/erq121

Wu, H. C., Huang, Y. C., Stracovsky, L., and Jinn, T. L. (2017). Pectin methylesterase is required for guard cell function in response to heat. Plant Signal. Behav. 12:e1338227. doi: 10.1080/15592324.2017.1338227

Wu, H. C., and Jinn, T. L. (2010). Heat shock-triggered Ca2+ mobilization accompanied by pectin methylesterase activity and cytosolic $\mathrm{Ca} 2+$ oscillation are crucial for plant thermotolerance. Plant Signal. Behav. 5, 1252-1256. doi: 10.4161/psb.5.10.12607

Wu, H. C., and Jinn, T. L. (2012). Oscillation regulation of Ca2+/calmodulin and heat-stress related genes in response to heat stress in rice (Oryza sativa L.). Plant Signal. Behav. 7, 1056-1057. doi: 10.4161/psb.21124

Wu, H. C., Luo, D. L., Vignols, F., and Jinn, T. L. (2012). Heat shockinduced biphasic $\mathrm{Ca} 2+$ signature and OsCaM1-1 nuclear localization mediate downstream signalling in acquisition of thermotolerance in rice (Oryza sativa L.). Plant Cell Environ. 35, 1543-1557. doi: 10.1111/j.1365-3040.2012.02 508. $\mathrm{x}$

Xiao, C., and Anderson, C. (2013). Roles of pectin in biomass yield and processing for biofuels. Front. Plant Sci. 4:67. doi: 10.3389/fpls.2013.00067

Xiong, J., Yang, Y., Fu, G., and Tao, L. (2015). Novel roles of hydrogen peroxide $(\mathrm{H} 2 \mathrm{O} 2)$ in regulating pectin synthesis and demethylesterification in the cell wall of rice (Oryza sativa) root tips. New Phytol. 206, 118-126. doi: 10.1111/nph. 13285

Xu, J., Tian, J., Belanger, F. C., and Huang, B. (2007). Identification and characterization of an expansin gene AsEXP1 associated with heat tolerance in C3 Agrostis grass species. J. Exp. Bot. 58, 3789-3796. doi: 10.1093/jxb/er $\mathrm{m} 229$

Yang, C. M., and Heilman, J. L. (1991). Short-term high temperature effects on stomatal behaviors of rice plants. ?. Occurring at the grain-filling stage. J. Agric. Res. China 40, 243-247.

Yang, K. A., Lim, C. J., Hong, J. K., Park, C. Y., Cheong, Y. H., Chung, W. S., et al. (2006). Identification of cell wall genes modified by a permissive high temperature in Chinese cabbage. Plant Sci. 171, 175-182. doi: 10.1016/j.plantsci. 2006.03.013

Yang, S., Huang, C., Wu, Z., Hu, J., Li, T., Liu, S., et al. (2006). Stomatal movement in response to long distance-communicated signals initiated by heat shock in partial roots of Commelina communis L. Sci. China Life Sci. 49, 18-25. doi: 10.1007/s11427-005-0117-8

Yang, T., and Poovaiah, B. W. (2002). A calmodulin-binding/CGCG box DNAbinding protein family involved in multiple signaling pathways in plants. J. Biol. Chem. 277, 45049-45058. doi: 10.1074/jbc.M207941200

York, W. S., Kumar Kolli, V. S., Orlando, R., Albersheim, P., and Darvill, A. G. (1996). The structures of arabinoxyloglucans produced by solanaceous plants. Carbohydr. Res. 285, 99-128. doi: 10.1016/S0008-6215(96) 90176-7

Yu, E., Fan, C., Yang, Q., Li, X., Wan, B., and Dong, Y. (2014). Identification of heat responsive genes in Brassica napus siliques at the seed-filling stage through transcriptional profiling. PLoS One 9:e101914. doi: 10.1371/journal. pone.0101914

Zhu, J., Lee, B. H., Dellinger, M., Cui, X., Zhang, C., Wu, S., et al. (2010). A cellulose synthase-like protein is required for osmotic stress tolerance in Arabidopsis. Plant J. 63, 128-140. doi: 10.1111/j.1365-313X.2010. 04227.x

Conflict of Interest Statement: The authors declare that the research was conducted in the absence of any commercial or financial relationships that could be construed as a potential conflict of interest.

Copyright $\odot 2018 \mathrm{Wu}$, Bulgakov and Jinn. This is an open-access article distributed under the terms of the Creative Commons Attribution License (CC BY). The use, distribution or reproduction in other forums is permitted, provided the original author(s) and the copyright owner(s) are credited and that the original publication in this journal is cited, in accordance with accepted academic practice. No use, distribution or reproduction is permitted which does not comply with these terms. 